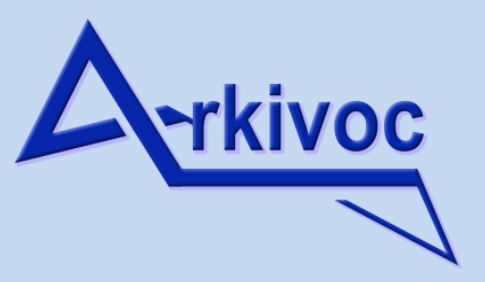

Free to Authors and Readers
A Platinum Open Access Journal for Organic Chemistry

Paper

DOAJ Seal
Arkivoc 2021, part iv, 168-185

\title{
Synthesis of ABO blood group antigens and functional glycan display on the cell surface
}

\section{Masato Tsutsui, ${ }^{a}$ Yoshiyuki Manabe, ${ }^{* a, b}$ Kazuya Kabayama, ${ }^{a, b}$ and Koichi Fukase ${ }^{* a, b}$}

${ }^{a}$ Department of Chemistry, Graduate School of Science, Osaka University, 1-1 Machikaneyama-cho, Toyonaka, Osaka 560-0043, Japan

${ }^{b}$ Core for Medicine and Science Collaborative Research and Education, Project Research Center for Fundamental Sciences, Osaka University, 1-1 Machikaneyama-cho, Toyonaka, Osaka 560-0043, Japan Email: koichi@chem.sci.osaka-u.ac.jp

Received 09-11-2020

Accepted 11-03-2020

Published on line 11-18-2020

\section{Abstract}

ABO blood group antigens are involved in various biological phenomena, including immune responses and infections. We achieved efficient and scalable synthesis of $A, B$, and $H$ antigens. Using chemical conjugation, synthesized $B$ antigen was displayed on the surface of living cells and its function as an antigen was confirmed by the IgM antibody recognition. Our results indicate that the multivalent interactions induced by cell surface glycan clustering are crucial in this system. The prepared cells displaying the glycan antigen are expected to be a model cell for investigating $A B O$ antigen function.

$<$ The cell displaying synthetic glycan >

$\rightarrow$ Model for investigating of glycan function

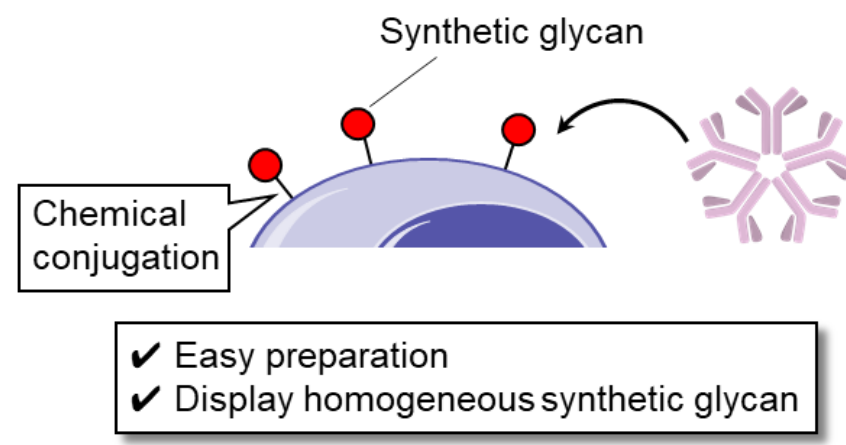

Keywords: ABO blood antigens, glycan engineering, IgM antibody, multivalency 


\section{Introduction}

Glycans are involved in various biological phenomena, including cell migration, cell development, signal transduction, and disease progression. ${ }^{1-3}$ Glycans cover the cell surface as a glycocalyx, consisting of glycoproteins and glycolipids, and provide the milieu for the first contact with the external environment. Therefore, glycans are closely related to self-recognition and non-self-recognition, such as infections and immune responses. On the other hand, the structural diversity and heterogeneity of glycans make it difficult to elucidate their functions at the molecular level. Thus, chemical synthesis, which provides a certain amount of pure glycans, is a powerful tool for investigating of the biological functions of glycans.

$A B O$ blood types are categorized by the glycan structure on erythrocytes (Figure 1a). Individuals of $O$, $A$, and $B$ blood types express $H, A$, and $B$ antigens, respectively, with $H$ antigen is a precursor of $A$ and $B$ antigens. $\mathrm{ABO}$ blood group glycans act as antigens and individuals produce antibodies, mainly IgM antibodies, against the glycans they do not express. The interaction of $A B O$ blood antigens with their antibodies results in blood agglutination. ${ }^{4}$ Such immune responses are extremely important in considering blood transfusions. In addition, $\mathrm{ABO}$ blood group glycans are expressed on a wide range of organs, including epithelium, intestine, gastric, and pancreas, and thereby, are closely associated to various diseases. ${ }^{5}$ Some pathogens, such as Norwalk virus and Helicobacter pylori, are reported to recognize $A B O$ blood group glycans. ${ }^{6-7}$ Subsequent to the first synthesis of $B$ antigen by Lemieux et al., many groups have reported the chemical syntheses of $A B O$ blood group glycans..$^{8-19}$
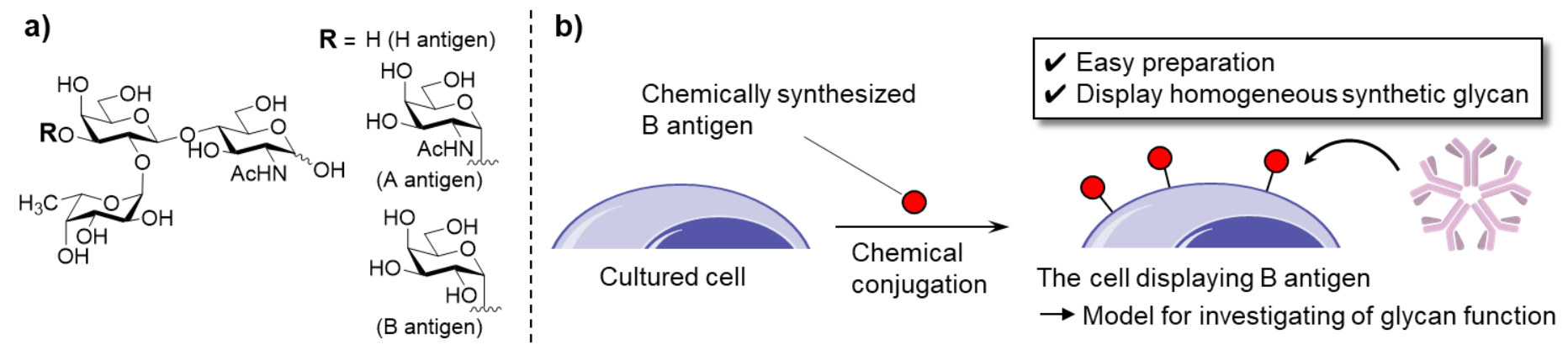

Figure 1. a) Chemical structure of $A B O$ blood group glycans. b) Preparation schematic of cells displaying synthetic antigen glycan using chemical conjugation.

Cell surface glycan engineering is a powerful tool for investigating and revealing glycan functions. ${ }^{20}$ Genetic approaches, including the knockout or knockdown of glycosyltransferase, are the most classical and versatile methods and have played a pivotal role in elucidating glycan functions. Bertozzi et al. developed metabolic labeling by incorporating unnatural monosaccharide analogs having the reaction handle followed by the bioorthogonal reaction. ${ }^{21}$ This method provides a facile platform for installing new chemical functionality to glycans. Chemical ${ }^{22-23}$ and chemoenzymatic ${ }^{24-27}$ glycan engineering have also been reported. In addition, de novo glycan display has also been investigated, such as the direct introduction of defined glycan structures into plasma membranes by lipid insertion, liposomal fusion, and tag technology. ${ }^{28-33}$ Henry et al. reported A and $B$ antigen display on erythrocytes using synthetic glycolipids. ${ }^{29}$ Palcic et al. reported $B$ antigen introduction onto cell surface by enzymatic labeling. ${ }^{34}$

In the current study, we synthesized ABO blood group glycans and investigated the display of the synthesized glycans on the cell surface. We achieved efficient and scalable synthesis of ABO blood group 
glycans. Synthesized B antigen was introduced onto the surface of living cells by chemical conjugation using $N$ hydroxysuccinimide (NHS) ester (Figure 1b). This approach allowed the display of homogeneous synthetic glycans on the cell surface with easy operation. Furthermore, B antigen displayed by this method was recognized by IgM antibody specific for B antigen glycan. In contrast, the IgM antibody did not interact with $B$ antigen introduced onto the IgG antibody. These results indicate that multivalent interactions through cell surface glycan clustering are crucial for the function of B antigen glycans as an antigen. The prepared cells displaying antigen glycan is expected to be a useful model for investigating $A B O$ antigen function.

\section{Results and Discussion}

The synthetic plan of $\mathrm{H}, \mathrm{A}$, and $\mathrm{B}$ antigens is shown in Scheme 1 . We synthesized ABO blood group type II antigens, which are widely expressed in the human body. We initiated the synthesis from galactose derivative 1, which had the orthogonal protecting groups (tert-butyl(dimethyl)silyl (TBS) and fluorenylmethoxycarbonyl protecting group (Fmoc)) at the glycan elongation sites. Many previous reports on the synthesis of ABO blood

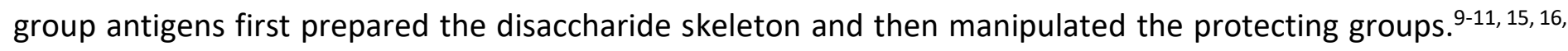
18, 19 In this study, orthogonally protected galactose fragment $\mathbf{1}$ was utilized to enable the straightforward synthesis of $A B O$ blood group antigens. $\beta$-Selective galactosylation between $\mathbf{1}$ and $\mathbf{2}$ using neighboring group participation of Fmoc group yielded disaccharide 3. After cleavage of Fmoc group, $\alpha$-fucosylation with $\mathbf{4}$ produced trisaccharide $\mathbf{5}$. Trisaccharide $\mathbf{5}$ can be used as a common intermediate; $\mathrm{H}$-antigen can be obtained by deprotection, whereas $A$ and B antigens can be obtained by cleavage of TBS group followed by $\alpha$ galactosaminylation and $\alpha$-galactosylation, respectively. The allyl group at the reducing termini of 5, 8, and $\mathbf{9}$ can be used as handles for bioconjugation.

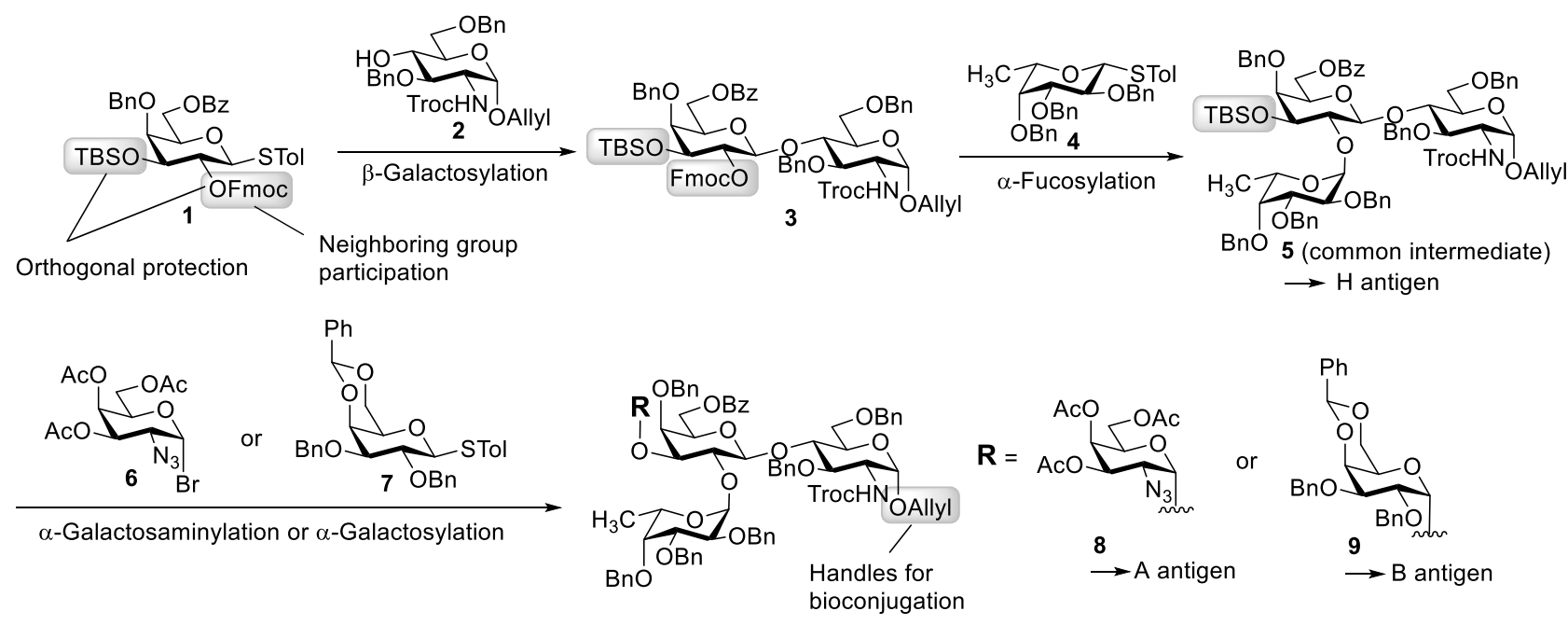

Scheme 1. Synthetic strategy of $H, A$, and B antigens.

Synthesis of $\mathrm{H}$ antigen 16 is shown in Scheme 2. Compound 10, reported previously by our group, ${ }^{35}$ was converted to a galactosyl donor 1 . Selective cleavage of benzylidene ${ }^{36}$ followed by benzoyl protection generated 1. Glycosylation between 1 and $\mathbf{2}^{37}$ using NIS and $\mathrm{TfOH}^{38}$ as activators afforded $\mathbf{3}$ with perfect $\beta$ selectivity due to neighboring group participation. In all case in this study, the stereochemistries produced by glycosylations were determined by the coupling constants at the anomeric positions. Cleavage of Fmoc group resulted 12, which was then fucosylated with $4^{39}$ to produce 5 in $88 \%$ yield with perfect $\alpha$-selectivity. 
With the common intermediate $\mathbf{5}$ in hand, $\mathrm{H}$ antigen $\mathbf{1 6}$ was synthesized via deprotection and introduction of the carboxylic acid for bioconjugation. After cleavage of TBS with HF.pyridine, Troc group of 13 was converted to acetamide through the reduction of azide followed by acetylation. In this step, the 3 position of galactose was also acetylated. A carboxy methyl group was then introduced to the reducing terminal of 14 by olefin metathesis reaction with methyl acrylate to yield $\mathbf{1 5}$. Global deprotection of $\mathbf{1 5}$ by hydrogenation and hydrolysis afforded $\mathrm{H}$ antigen 16.

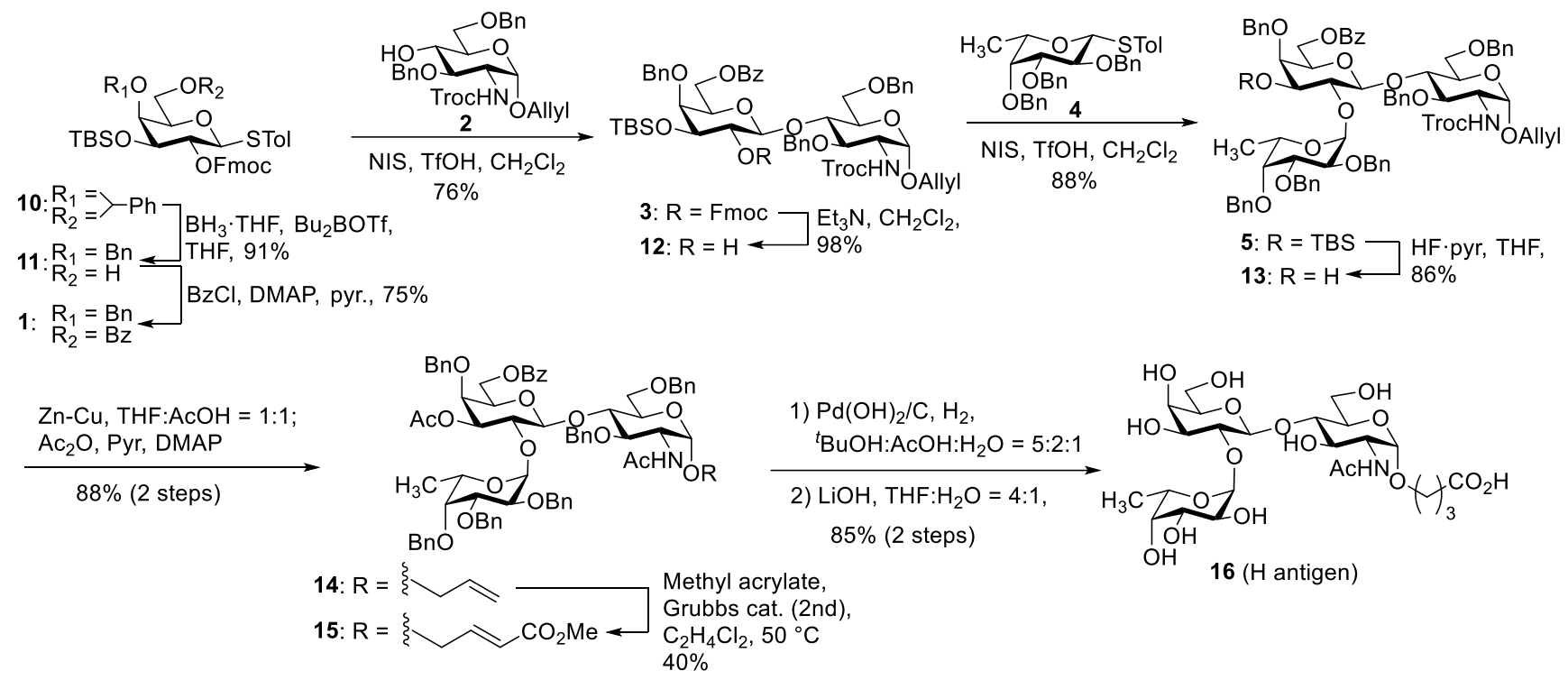

Scheme 2. Synthesis of $\mathrm{H}$ antigen 15.

A antigen 18 and B antigen 20 were synthesized from 13 (Scheme 3). Glycosylation with 2-azido galactosaminyl donor $6^{40}$ using $\mathrm{AgClO}_{4}{ }^{41}$ gave protected $\mathrm{A}$ antigen 17 in $90 \%$ with perfect $\alpha$-selectivity. Synthesis of $A$ antigen 18 was then completed via introduction of carboxylic acid and deprotection, as was done in the synthesis of $\mathrm{H}$ antigen 15. $\mathrm{B}$ antigen $\mathbf{2 0}$ was similarly synthesized. After $\alpha$-selective galactosylation with 7, ${ }^{42}$ the resulting 19 was converted to B antigen 20.

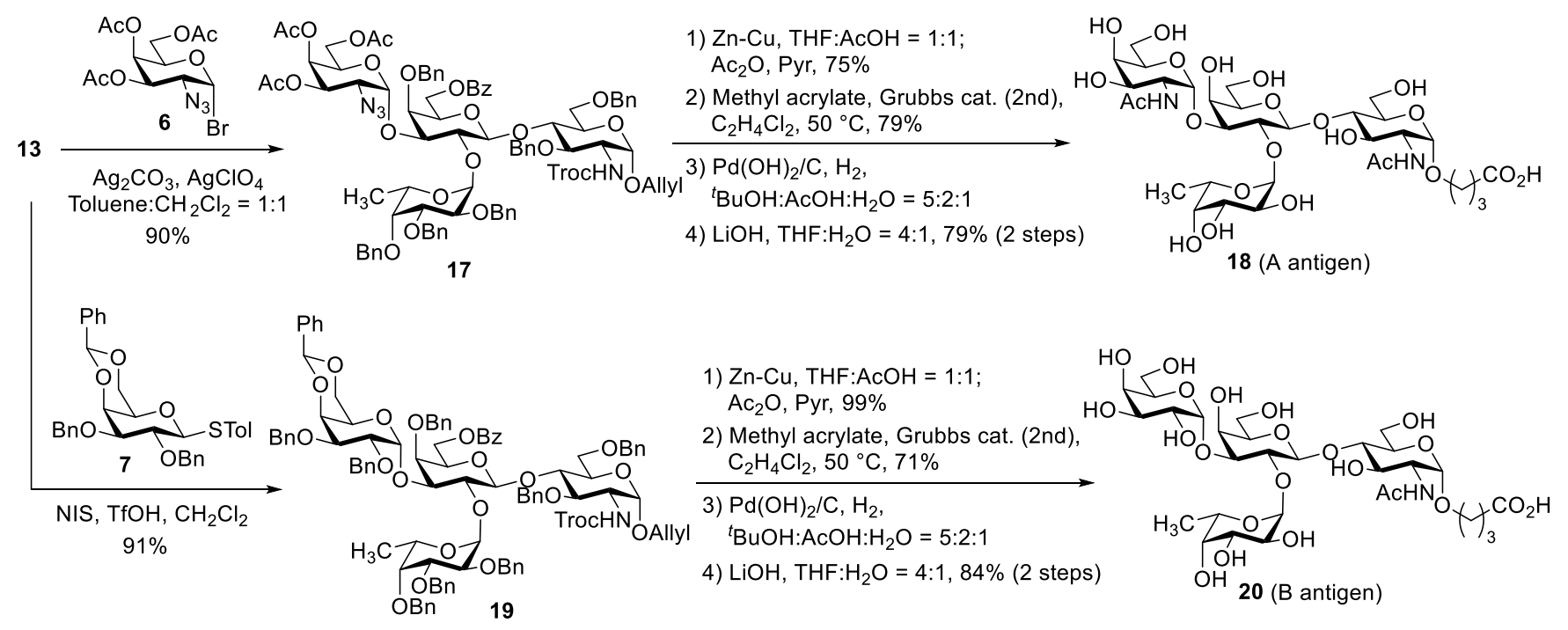

Scheme 3. Synthesis of A antigen 18 and B antigen 20. 
With $\mathrm{ABO}$ blood group antigens in hand, we investigated the introduction of synthetic glycan onto the cell surface (Figure 2). We herein used B-cell lymphoma Raji cells and B antigen. We employed direct chemical conjugation of glycan onto the cell surface proteins using NHS ester, as well as indirect labeling using glycanantibody conjugates (Figure 2c). In the indirect method, anti-CD20 antibody, which is used for the treatment of B-cell lymphoma, was applied as Raji cell recognition antibody.

a)

b)

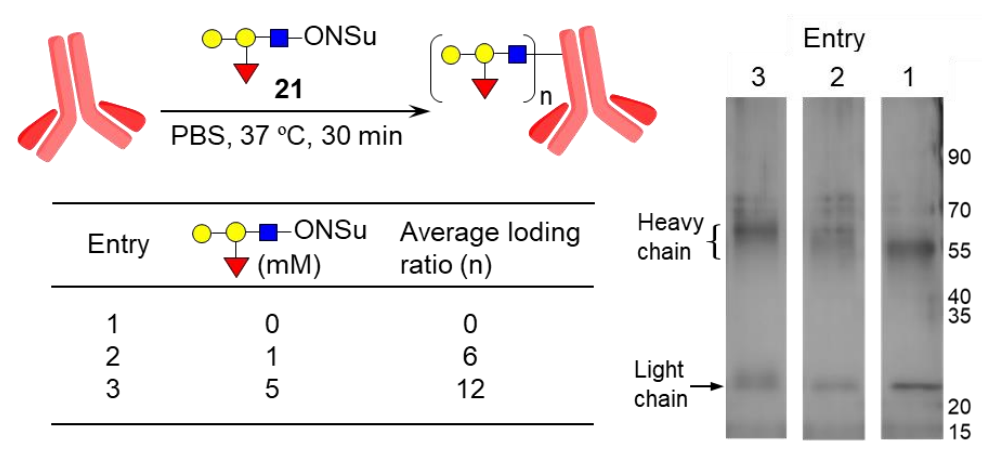

c)
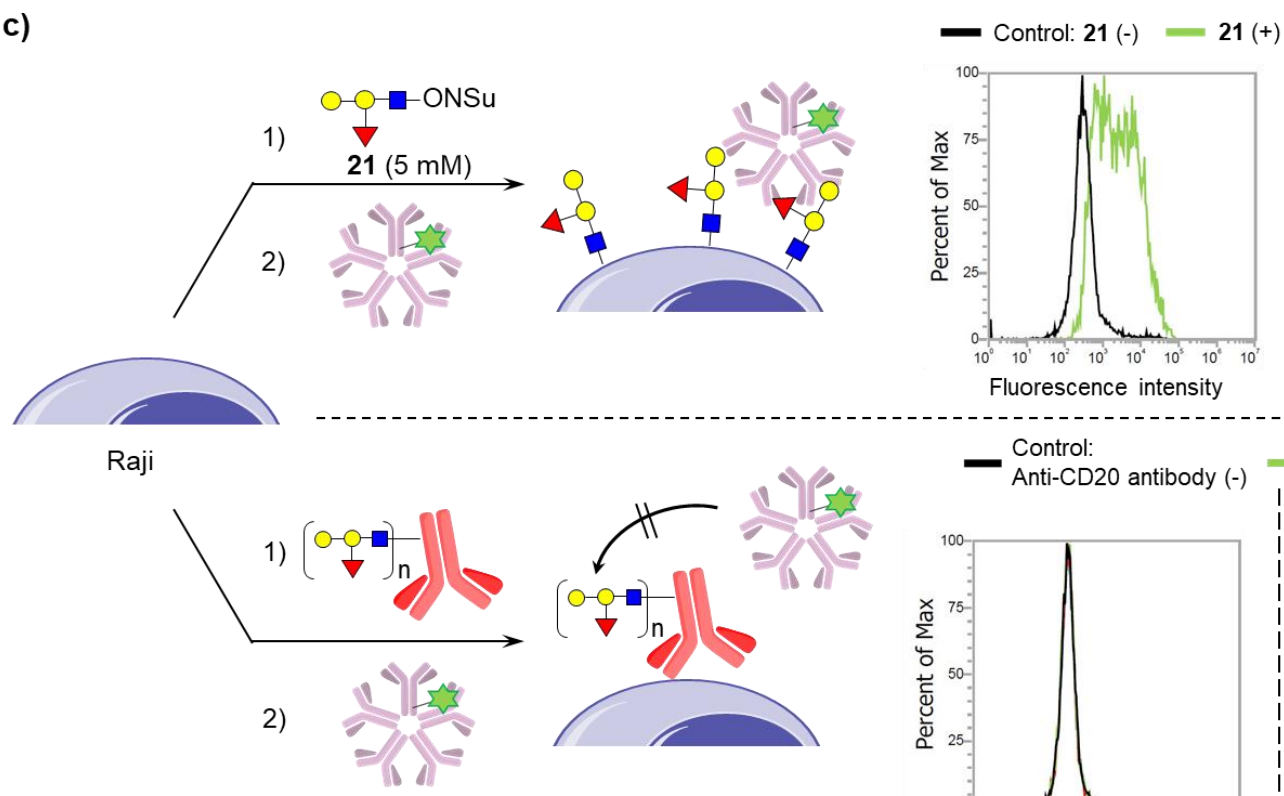

Fluorescence intensity

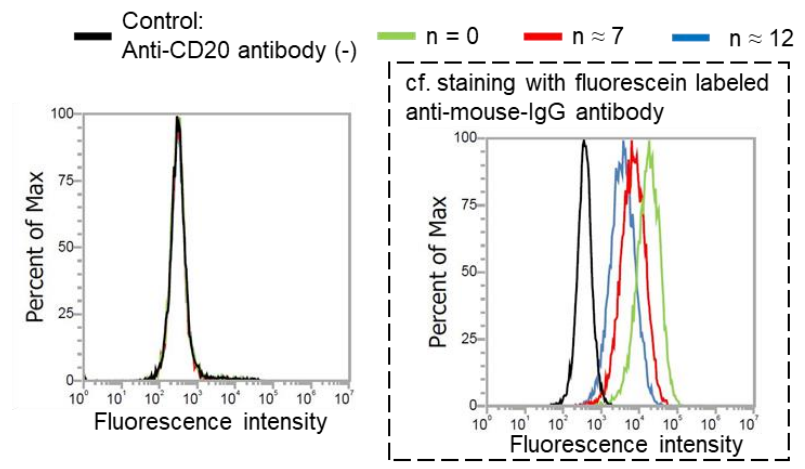

Figure 2. a) Preparation of $B$ antigen NHS ester 20. b) Preparation of B antigen-antibody conjugate. c) B antigen labeling of cell surfaces and evaluation of the labeled cells using anti-B antigen IgM antibody.

B antigen labeling reagents, B antigen NHS ester 21, and B antigen-antibody conjugate were readily prepared. Treatment of $\mathbf{2 0}$ with $N, N, N^{\prime}, N^{\prime}$-tetramethyl-O-(N-succinimidyl)uronium tetrafluoroborate (TSTU) yielded B antigen NHS ester 21 (Figure 2a). Reaction of anti-CD20 antibody with two concentrations of 21 (0, 1.0 , and $5.0 \mathrm{mM}$ ) in PBS at $4{ }^{\circ} \mathrm{C}$ for $30 \mathrm{~min}$ afforded the antibodies conjugated with various loading ratios of $\mathrm{B}$ antigen (Figure $2 \mathrm{~b}$ ). Based on SDS-PAGE analysis, the loading ratio of $\mathrm{B}$ antigen increased as the concentration of $\mathbf{2 1}$ was increased. The average loading ratios $(\mathrm{n})$ were estimated to be 7 and 12 when 1.0 and $5.0 \mathrm{mM} 21$ was used, respectively. 
After labeling Raji cell with B antigen using B antigen NHS ester $\mathbf{2 1}$ or B antigen-antibody conjugate, the interaction with IgM antibody specific for $B$ antigen glycan was determined using flow cytometry to evaluate the function of the $B$ antigen displayed on the cell surface (Figure $2 \mathrm{c}$ ). The treatment of Raji cell with $5.0 \mathrm{mM}$ 21 in PBS at $37{ }^{\circ} \mathrm{C}$ for 30 min did not decrease cell viability, and the treated cells were successfully recognized by the fluorescein-labeled anti-B antigen IgM antibody. In contrast, cells treated with $B$ antigen-antibody conjugates were not recognized by the IgM antibody. Considering the successful staining with the fluoresceinlabeled anti-mouse IgG antibody, these results showed that B antigen loaded on anti-CD20 antibody was not recognized by the IgM antibody. In our previous report using $\alpha$-gal as a glycan antigen, we demonstrated $\alpha$-gal conjugated to anti-CD20 antibody in the same manner described in the current study was recognized by antibodies against $\alpha$-gal, ${ }^{43}$ suggesting that accessibility of the glycan antigen on anti-CD20 antibody does not the issue. The difference in recognition of $B$ antigen and $\alpha$-gal might be attributed to the binding affinity of the corresponding antibodies as antibodies against $\alpha$-gal contain a certain amount of IgG antibodies, which exhibit high affinity.

The results described above indicate that the method used for glycan displaying is important for synthetic glycans to exhibit their function on the cell surface. Although individual glycan recognition in nature is usually weak, multiple glycans on the cell surface provide multivalent interactions leading to strong avidity. ${ }^{44-45}$ Such multivalency plays a crucial role in glycan recognition. Glycan-receptor interaction on the cell surface can be enhanced by multivalency of receptor or glycan clustering. ${ }^{46-48}$ In the presence of a multivalent binding partner, membrane proteins can diffuse in lipid bilayer to form clusters. IgM antibodies have 10 antigen-binding sites and exhibit multivalent interactions. ${ }^{49-50}$ When $\mathrm{B}$ antigen was introduced to the membrane proteins using NHS ester $\mathbf{2 1}$, the clustering mechanism was expected to enhance the interaction between $B$ antigen displayed on the cell surface and IgM antibody. However, B antigen introduced onto the anti-CD20 antibody was not flexible, and thereby, may not provide multivalent interaction with IgM antibody. Multivalent interaction by CD20 clustering might be prevented by steric hindrance of anti-CD20 antibody. These results demonstrated that reconstruction of multivalent interaction is crucial for the functional display of synthetic glycans in biological systems. $A B O$ blood group glycans are known to primarily exist on glycolipids and are also expressed on glycoproteins as $\mathrm{N}$-glycans and $\mathrm{O}$-glycans. However, their recognition on glycoproteins by the IgM antibodies has not been elucidated. Glycan display using NHS ester $\mathbf{2 1}$ is usually directed against amines on proteins to produce pseudo-glycoproteins. Thus, the current study suggests that ABO blood group glycans on glycoproteins can also be recognized by IgM antibodies through their clustering and can induce biological events.
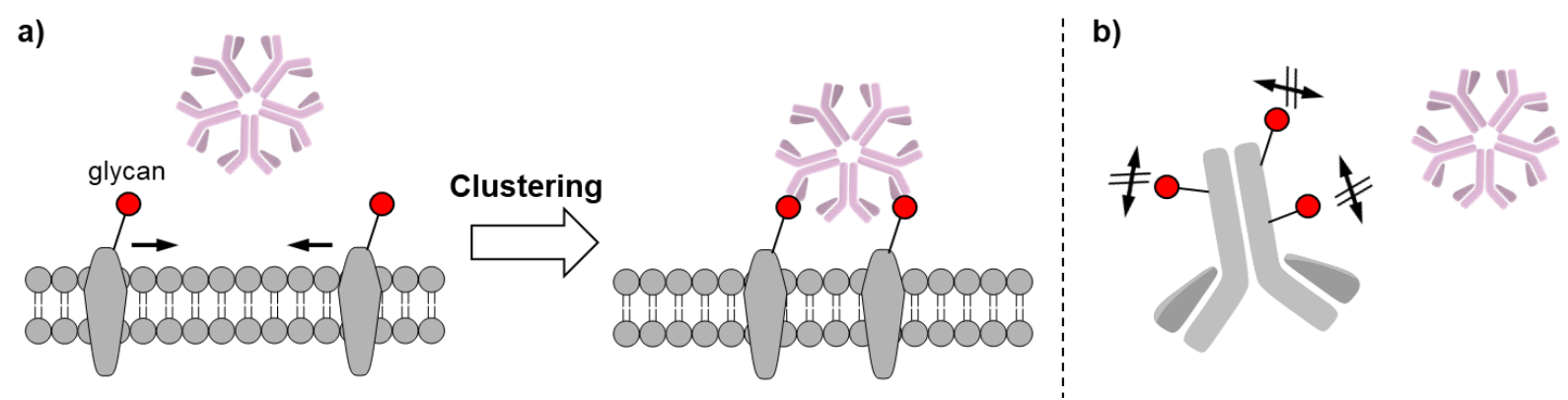

Figure 3. Putative interaction of $B$ antigen with IgM antibody. a) B antigen (red circle) chemically conjugated to the cell surface membrane protein. b) B antigen chemically conjugated to IgG antibody. 


\section{Conclusions}

We synthesized ABO blood group glycans and achieved functional display of $B$ antigen on the surface of a living cells. Importantly, our synthesis was efficient and scalable. Orthogonal protection strategy enabled the straightforward synthesis of $A B O$ blood group antigens. All glycosylations proceeded in more than $70 \%$ yield with perfect stereoselectivity and each glycan $(\mathbf{1 6}, \mathbf{1 8}$, and $\mathbf{2 0}$ ) was procured at quantities greater than $50 \mathrm{mg}$. Synthesized B antigen was displayed on the cell surface in two ways, direct chemical conjugation using NHS ester $\mathbf{2 1}$ and indirect labeling using the glycan-antibody conjugate. B antigen directly conjugated onto cell surface proteins was recognized by IgM antibody, whereas B antigen conjugated onto IgG antibody was not recognized. These results indicate that the multivalent interactions induced by glycan clustering are important for the emergence of proper glycan function on the cell surface. Our future work will include using this newly developed approach for displaying "functional" synthetic glycan antigen on the cell surface to elucidate ABO antigen function in various biological phenomena, including immune responses and pathogen infections.

\section{Experimental Section}

General. ${ }^{1} \mathrm{H}$ and ${ }^{13} \mathrm{C}$ NMR spectra were recorded in an indicated solvent with JEOL ECA $500 \mathrm{MHz}$ spectrometer. Chemical shifts of ${ }^{1} \mathrm{H}$ and ${ }^{13} \mathrm{C}$ NMR were referenced to the solvent peaks: $\delta=7.26$ and $\delta=77.16$ for $\mathrm{CDCl}_{3}, \delta=3.30$ and $\delta=49.30$ for $\mathrm{CD}_{3} \mathrm{OD}$. Multiplicities abbreviations: $\mathrm{s}=$ singlet, $\mathrm{d}=$ doublet, $\mathrm{t}=$ triplet, $\mathrm{q}=$ quartet, $\mathrm{m}=$ multiplet, $b r=$ broad. High-resolution mass spectra were recorded on a ESI-LTQ-Orbitrap XL (FTMS) mass spectrometer and ESI-Q-TOF mass spectrometer. Chemical purification was carried out using silica-gel column chromatography. Silica-gel column chromatography was carried out using Silica Gel 60N (Kanto Chemical Co., 40-50 $\mu \mathrm{m}$ or $63-210 \mu \mathrm{m})$ at medium pressure $\left(1-4 \mathrm{~kg} \mathrm{~cm}^{-2}\right)$. Gel permeation chromatography was carried out using Sephadex LH-20 at atmospheric pressure. Silica-gel 60 F254 (Merck Co.) was used for TLC analysis and preparative TLC purification, and compounds were visualized by UV (254 nm), $p$-methoxybenzaldehyde ( $p$ anisaldehyde, $0.03 \%$ in $\mathrm{EtOH}-\mathrm{H}_{2} \mathrm{SO}_{4}$-acetic acid buffer). Anhydrous $\mathrm{CH}_{2} \mathrm{Cl}_{2}$ were distilled in the presence of calcium hydride. Anhydrous THF, DMF, distilled water, and toluene were purchased from FUJIFILM Wako Pure Chemical Corporation, Ltd.. Nonaqueous reactions were carried out under argon atmosphere. Molecular sieve 4A (MS4A) was activated with a microwave and dried in vacuo for 3 times before use. All other commercially available reagents and solvents were used as purchased.

4-Methylphenyl 4-O-benzyl-3-O-tert-butyldimethylsilyl-2-O-9-fluorenylmethyloxycarbonyl-1-thio- $\beta$-Dgalactopyranoside (11). To a solution of $\mathbf{1 0}(20.5 \mathrm{mg}, 28.83 \mu \mathrm{mol})$ in THF $(290 \mu \mathrm{L})$ were added $1.0 \mathrm{M} \mathrm{BH} \cdot \mathrm{THF}$ (288.3 $\mu \mathrm{L}, 288.3 \mu \mathrm{mol})$ and $1.0 \mathrm{M} \mathrm{Bu}{ }_{2} \mathrm{BOTf} \cdot \mathrm{CH}_{2} \mathrm{Cl}_{2}(28.83 \mu \mathrm{L}, 28.83 \mu \mathrm{mol})$ at $0{ }^{\circ} \mathrm{C}$ under Ar atmosphere. After being stirred for $10.5 \mathrm{~h}$ at $0{ }^{\circ} \mathrm{C}$ and the reaction was quenched with $\mathrm{MeOH}$ and sat. $\mathrm{NaHCO}_{3}$ aq. and extracted with $\mathrm{CHCl}_{3}$. The organic layer was dried over $\mathrm{Na}_{2} \mathrm{SO}_{4}$, filtered, and concentrated in vacuo. The residue was purified by silica-gel column chromatography (toluene/EtOAc 25/1) to give $\mathbf{1 1}(18.7 \mathrm{mg}, 91 \%)$ as a white solid. ${ }^{1} \mathrm{H}$ NMR $\left(500 \mathrm{MHz}, \mathrm{CDCl}_{3}\right): \delta 7.77$ (d, J 7.6 Hz, 2H), 7.68 (dd, J 12.7, 7.6 Hz, 2H), 7.44-7.37 (m, 4H), 7.37-7.28 (m, $7 \mathrm{H}), 7.05(\mathrm{~d}, J 7.9 \mathrm{~Hz}, 2 \mathrm{H}), 5.18(\mathrm{t}, J 9.7 \mathrm{~Hz}, 1 \mathrm{H}), 5.05(\mathrm{~d}, J 11.6 \mathrm{~Hz}, 1 \mathrm{H}), 4.64(\mathrm{~d}, J 10.0 \mathrm{~Hz}, 1 \mathrm{H}), 4.64$ (dd, J 10.2, $7.0 \mathrm{~Hz}, 1 \mathrm{H}), 4.57(\mathrm{~d}, J 11.6 \mathrm{~Hz}, 1 \mathrm{H}), 4.31(\mathrm{t}, J 7.0 \mathrm{~Hz}, 1 \mathrm{H}), 4.24(\mathrm{dd}, J 10.2,7.0 \mathrm{~Hz}, 1 \mathrm{H}), 3.88(\mathrm{dd}, J$ J 10.0, $2.7 \mathrm{~Hz}$, $1 \mathrm{H}), 3.86-3.80(\mathrm{~m}, 1 \mathrm{H}), 3.73(\mathrm{~d}, J 2.7 \mathrm{~Hz}, 1 \mathrm{H}), 3.58-3.51(\mathrm{~m}, 2 \mathrm{H}), 2.35(\mathrm{~s}, 1 \mathrm{H}), 2.30(\mathrm{~s}, 3 \mathrm{H}), 0.88(\mathrm{~s}, 9 \mathrm{H}), 0.16(\mathrm{~s}$, $3 \mathrm{H}), 0.11(\mathrm{~s}, 3 \mathrm{H}) .{ }^{13} \mathrm{C} \mathrm{NMR}\left(500 \mathrm{MHz}, \mathrm{CDCl}_{3}\right): \delta$ 154.39, 145.65, 143.51, 143.22, 141.29, 141.22, 138.26, 137.76, $132.47,129.58,129.51,129.00,128.36,127.96,127.83,127.78,127.75,127.15,127.06,125.47,125.15$, 
125.09, 119.99, 119.96, 119.90, 87.00, 78.81, 76.63, 75.56, 74.83, 74.75, 70.08, 62.09, 46.69, 25.56, 21.10, 17.88, -4.17, -5.14. HRMS (ESI-LTQ-Orbitrap) $\mathrm{m} / z$ [M+Na]+ calcd for $\mathrm{C}_{41} \mathrm{H}_{48} \mathrm{O}_{7} \mathrm{SSiNa}, 735.2782$, found 735.2781.

4-Methylphenyl 4-O-benzyl-6-O-benzoyl-3-O-tert-butyldimethylsilyl-2-O-9-fluorenylmethyloxycarbonyl-1thio- $\beta$-D-galactopyranoside (1). To a solution of 11 (200.8 mg, $281.6 \mu \mathrm{mol}$ ) and $\mathrm{N}, \mathrm{N}$-dimethyl-4aminopyridine $(3.5 \mathrm{mg}, 28.16 \mu \mathrm{mol})$ in pyridine $(2.81 \mathrm{~mL})$ was added benzoyl chloride $(65.4 \mu \mathrm{L}, 563.3 \mu \mathrm{mol})$ at $0{ }^{\circ} \mathrm{C}$ under Ar atmosphere. After being stirred for $3.5 \mathrm{~h}$ at $\mathrm{rt}$, to the reaction solution were added $\mathrm{N}, \mathrm{N}$ dimethyl-4-aminopyridine $(3.4 \mathrm{mg}, 27.83 \mu \mathrm{mol})$ and benzoyl chloride $(65.0 \mu \mathrm{L}, 559.5 \mu \mathrm{mol})$ at $0{ }^{\circ} \mathrm{C}$. After being stirred for $3.5 \mathrm{~h}$ at $\mathrm{rt}$ and the reaction was quenched with sat. $\mathrm{NaHCO}_{3}$ aq. and extracted with $\mathrm{CHCl}_{3}$. The organic layer was dried over $\mathrm{Na}_{2} \mathrm{SO}_{4}$, filtered, and concentrated in vacuo. The residue was purified by silica-gel column chromatography (toluene/EtOAc 30/1) to give 1 (173.2 mg, 75\%) as a white solid. ${ }^{1} \mathrm{H} \mathrm{NMR} \mathrm{(500} \mathrm{MHz,}$ $\mathrm{CDCl}_{3}$ ): $\delta 8.00$ (dd, J 8.3, 1.1 Hz, 2H), $7.77(\mathrm{~d}, J 7.6 \mathrm{~Hz}, 2 \mathrm{H}), 7.68$ (dd, J 15.8, 7.4 Hz, 2H), 7.59 (tt, J 7.4, $1.1 \mathrm{~Hz}$, $1 \mathrm{H}), 7.48-7.25(\mathrm{~m}, 13 \mathrm{H}), 6.88(\mathrm{~d}, J 7.9 \mathrm{~Hz}, 2 \mathrm{H}), 5.21(\mathrm{t}, J 9.5 \mathrm{~Hz}, 1 \mathrm{H}), 5.11(\mathrm{~d}, J 11.3 \mathrm{~Hz}, 1 \mathrm{H}), 4.68-4.59(\mathrm{~m}, 3 \mathrm{H})$, 4.51 (dd, J 11.5, 7.6 Hz, 1H), 4.40 (dd, J 11.5, $4.6 \mathrm{~Hz}, 1 \mathrm{H}), 4.32$ (t, J 7.3 Hz, 1H), 4.24 (dd, J 10.3, 7.9 Hz, 1H), 3.91 (dd, J 9.5, 3.5 Hz, 1H), 3.85 (dd, J 7.6, $3.5 \mathrm{~Hz}, 1 \mathrm{H}$ ), 3.82 (d-br, J $2.0 \mathrm{~Hz}, 1 \mathrm{H}$ ), $2.24(\mathrm{~s}, 3 \mathrm{H}), 0.89(\mathrm{~s}, 9 \mathrm{H}), 0.17(\mathrm{~s}, 3 \mathrm{H})$, 0.12 (s, 3H). ${ }^{13} \mathrm{C}$ NMR $\left(500 \mathrm{MHz}, \mathrm{CDCl}_{3}\right): \delta 166.23,154.46,143.56,143.22,141.32,141.24,138.12,137.58$, $133.13,132.33,129.99,129.81,129.69,129.45,128.37,128.32,127.92,127.85,127.80,127.69,127.17$, $127.07,125.52,125.16,120.01,119.97,87.26,76.30,75.50,75.03,74.74,70.16,64.09,46.72,25.58,21.08$, $17.91,-0.03,-4.15,-5.13$.

HRMS (ESI-LTQ-Orbitrap) $m / z[\mathrm{M}+\mathrm{Na}]^{+}$calcd for $\mathrm{C}_{48} \mathrm{H}_{52} \mathrm{O}_{8} \mathrm{SSiNa}, 839.3044$, found 839.3046.

Allyl 3,6-di-O-benzyl-4-O-(4-O-benzyl-6-O-benzoyl-3-O-tert-butyldimethylsilyl-2-0-9-fluorenylmethyloxycarbonyl- $\beta$-D-galactopyranosyl)-2-(2,2,2-trichloroethoxycarbonylamino)-2-deoxy- $\alpha$-D-glucopyranoside (3). To a suspension of donor 1 (170.8 mg, $208.9 \mu \mathrm{mol})$, acceptor $2(100.1 \mathrm{mg}, 174.1 \mu \mathrm{mol}), N$-iodosuccinimide (47.9 mg, $208.9 \mu \mathrm{mol}$ ), and MS4A powder (ca. $300 \mathrm{mg}$ ) in $\mathrm{CH}_{2} \mathrm{Cl}_{2}(3.50 \mathrm{~mL}$ ) was added trifluoromethanesulfonic acid $(6.1 \mu \mathrm{L}, 69.65 \mu \mathrm{mol})$ at $-40{ }^{\circ} \mathrm{C}$ under Ar atmosphere. After being stirred for $1 \mathrm{~h}$ at $-40{ }^{\circ} \mathrm{C}$, the reaction was quenched with sat. $\mathrm{NaHCO}_{3}$ aq. and $10 \% \mathrm{Na}_{2} \mathrm{~S}_{2} \mathrm{O}_{3}$ aq. and extracted with $\mathrm{CHCl}_{3}$. The organic layer was dried over $\mathrm{Na}_{2} \mathrm{SO}_{4}$, filtered, and concentrated in vacuo. The residue was purified by silica-gel column chromatography (toluene/EtOAc 50/1 to 20/1) to give 3 (167.0 mg, 76\%) as a white solid. ${ }^{1} \mathrm{H} \mathrm{NMR} \mathrm{(500}$ $\mathrm{MHz}, \mathrm{CDCl}_{3}$ ): $\delta 7.96(\mathrm{~d}, J 7.0 \mathrm{~Hz}, 2 \mathrm{H}), 7.78(\mathrm{t}, J 7.5 \mathrm{~Hz}, 2 \mathrm{H}), 7.60$ (dd, J 7.5, $\left.1.1 \mathrm{~Hz}, 2 \mathrm{H}\right), 7.58-7.54(\mathrm{~m}, 1 \mathrm{H}), 7.48-$ $7.39(\mathrm{~m}, 4 \mathrm{H}), 7.33-7.27(\mathrm{~m}, 6 \mathrm{H}), 7.25-7.18(\mathrm{~m}, 8 \mathrm{H}), 7.18-7.11(\mathrm{~m}, 3 \mathrm{H}), 5.84-5.75(\mathrm{~m}, 1 \mathrm{H}), 5.19(\mathrm{dq}, J 17.3,1.5$ $\mathrm{Hz}, 1 \mathrm{H}), 5.12(\mathrm{dt}, J 11.7,1.3 \mathrm{~Hz}, 1 \mathrm{H}), 5.07(\mathrm{~d}, J 11.3 \mathrm{~Hz}, 1 \mathrm{H}), 5.05-4.98(\mathrm{~m}, 2 \mathrm{H}), 4.95(\mathrm{~d}, J 9.5 \mathrm{~Hz}, 1 \mathrm{H}), 4.89(\mathrm{~d}, J$ $3.6 \mathrm{~Hz}, 1 \mathrm{H}), 4.73(\mathrm{~d}, J 12.0 \mathrm{~Hz}, 1 \mathrm{H}), 4.66(\mathrm{~d}, J 12.0 \mathrm{~Hz}, 1 \mathrm{H}), 4.61-4.53(\mathrm{~m}, 3 \mathrm{H}), 4.50(\mathrm{~d}, J 11.3 \mathrm{~Hz}, 1 \mathrm{H}), 4.46(\mathrm{dd}, J$ $10.5,6.3 \mathrm{~Hz}, 1 \mathrm{H}), 4.36(\mathrm{~d}, J 8.0 \mathrm{~Hz}, 1 \mathrm{H}), 4.31(\mathrm{~d}, J 12.2 \mathrm{~Hz}, 1 \mathrm{H}), 4.26-4.20(\mathrm{~m}, 2 \mathrm{H}), 4.10-4.05(\mathrm{~m}, 1 \mathrm{H}), 4.05-3.96$ $(\mathrm{m}, 2 \mathrm{H}), 3.96-3.89(\mathrm{~m}, 2 \mathrm{H}), 3.69(\mathrm{dd}, J 11.0,2.9 \mathrm{~Hz}, 1 \mathrm{H}), 3.62-3.56(\mathrm{~m}, 3 \mathrm{H}), 3.50(\mathrm{dd}, J 9.7,2.9 \mathrm{~Hz}, 1 \mathrm{H}), 3.45(\mathrm{dd}$, J 11.0, $1.6 \mathrm{~Hz}, 1 \mathrm{H}), 3.40(\mathrm{t}, J 6.3 \mathrm{~Hz}, 1 \mathrm{H}), 0.88(\mathrm{~s}, 9 \mathrm{H}), 0.09(\mathrm{~s}, 3 \mathrm{H}), 0.01(\mathrm{~s}, 3 \mathrm{H}) .{ }^{13} \mathrm{C} \mathrm{NMR}\left(500 \mathrm{MHz}^{\mathrm{CDCl}}\right)_{3}: \delta$ $166.11,154.33,154.18,143.41,141.50,141.38,138.82,138.38,138.18,133.39,133.08,129.85,129.67$, $128.41,128.36,128.29,127.94,127.92,127.89,127.73,127.67,127.58,127.51,127.45,127.13,127.10$, $127.05,124.84,124.75,120.10,120.07,117.83,100.72,96.58,95.49,77.71,77.48,77.21,76.88,75.17,74.56$, 74.18, 72.99, 72.21, 70.71, 69.47, 68.33, 67.65, 62.96, 54.70, 46.83, 25.59, 17.88, -4.23, -5.21. HRMS (ESI-LTQOrbitrap) $\mathrm{m} / z[\mathrm{M}+\mathrm{Na}]^{+}$calcd for $\mathrm{C}_{67} \mathrm{H}_{74} \mathrm{Cl}_{3} \mathrm{NO}_{15} \mathrm{SiNa} 1290.3756$, found 1290.3781 .

Allyl 3,6-di-O-benzyl-4-O-(4-O-benzyl-6-O-benzoyl-3-O-tert-butyldimethylsilyl- $\beta$-D-galactopyranosyl)-2(2,2,2-trichloroethoxycarbonylamino)-2-deoxy- $\alpha$-D-glucopyranoside (12). To a solution of 3 (2.083 g, 1.643 $\mathrm{mmol})$ in $\mathrm{CH}_{2} \mathrm{Cl}_{2}(20.0 \mathrm{~mL})$ was added triethylamine $(5.0 \mathrm{~mL})$ at $\mathrm{rt}$ under Ar atmosphere. After being stirred for $16 \mathrm{~h}$ at $\mathrm{rt}$, the reaction mixture was diluted with toluene and concentrated in vacuo. The crude compound was azetropic-dried with toluene three times. The residue was purified by silica-gel column chromatography 
(Toluene/AcOEt 9/1 to 4/1) to give 12 (1.685 g, 98\%) as a light yellow solid. ${ }^{1} \mathrm{H}$ NMR (500 MHz, $\left.\mathrm{CDCl}_{3}\right): \delta 7.89$ (d, J 7.2 Hz, 2H), $7.51(\mathrm{t}, J 7.4 \mathrm{~Hz}, 1 \mathrm{H}), 7.38-7.29(\mathrm{~m}, 8 \mathrm{H}), 7.29-7.12(\mathrm{~m}, 9 \mathrm{H}), 5.90-5.80(\mathrm{~m}, 1 \mathrm{H}), 5.24(\mathrm{dq}, J 17.2$, $1.5 \mathrm{~Hz}, 1 \mathrm{H}), 5.19(\mathrm{dq}, J 10.4,1.2 \mathrm{~Hz}, 1 \mathrm{H}), 5.05(\mathrm{~d}, J 11.5 \mathrm{~Hz}, 1 \mathrm{H}), 4.97(\mathrm{~d}, J 10.0 \mathrm{~Hz}, 1 \mathrm{H}), 4.94(\mathrm{~d}, J 11.5 \mathrm{~Hz}, 1 \mathrm{H})$, $4.88(\mathrm{~d}, J 3.6 \mathrm{~Hz}, 1 \mathrm{H}), 4.72-4.63(\mathrm{~m}, 4 \mathrm{H}), 4.57-4.52(\mathrm{~m}, 3 \mathrm{H}), 4.33(\mathrm{dd}, J 11.1,6.1 \mathrm{~Hz}, 1 \mathrm{H}), 4.19(\mathrm{t}, J 5.5 \mathrm{~Hz}, 1 \mathrm{H})$, 4.17-4.13 (m, 1H), 4.13-4.10 (m, 1H), $4.05(\mathrm{dd}, J 11.5,3.0 \mathrm{~Hz}, 1 \mathrm{H}), 3.99-3.92(\mathrm{~m}, 2 \mathrm{H}), 3.85-3.80(\mathrm{~m}, 1 \mathrm{H}), 3.79-$ $3.71(\mathrm{~m}, 2 \mathrm{H}), 3.69$ (dd, J 11.5, $1.7 \mathrm{~Hz}, 1 \mathrm{H}), 3.62(\mathrm{~d}, J 2.3 \mathrm{~Hz}, 1 \mathrm{H}), 3.55(\mathrm{dd}, J$ 9.5, $2.8 \mathrm{~Hz}, 1 \mathrm{H}), 3.51(\mathrm{t}, J 6.2 \mathrm{~Hz}$, $1 \mathrm{H}), 3.18$ (d, J $2.1 \mathrm{~Hz}, 1 \mathrm{H}), 0.94(\mathrm{~s}, 9 \mathrm{H}), 0.13(\mathrm{~s}, 3 \mathrm{H}), 0.11(\mathrm{~s}, 3 \mathrm{H}) .{ }^{13} \mathrm{C} \mathrm{NMR}\left(500 \mathrm{MHz}, \mathrm{CDCl}_{3}\right): \delta 175.66,169.56$, $166.05,138.93,137.62,133.02,129.82,129.57,128.45,128.34,128.24,127.96,127.79,127.75,127.69$, $127.51,127.48,127.07,126.53,126.32,126.06,125.84,125.77,125.60,125.56,102.81,98.22,77.38,77.35$, 77.20, 76.91, 75.98, 75.34, 75.08, 74.83, 73.58, 73.21, 72.68, 72.49, 71.14, 70.57, 68.22, 63.66, 63.41, 59.29, 51.87, 26.68, 25.90, 23.99, 18.27, -4.42, -4.47. HRMS (ESI-LTQ-Orbitrap) $\mathrm{m} / \mathrm{z}[\mathrm{M}+\mathrm{Na}]^{+}$calcd for $\mathrm{C}_{52} \mathrm{H}_{64} \mathrm{Cl}_{3} \mathrm{NO}_{13} \mathrm{SiNa} 1068.3075$, found 1068.3083 .

Allyl 3,6-di-O-benzyl-4-O-(4-O-benzyl-2-O-(2,3,4-tri-O-benzyl- $\alpha$-L-fucopyranosyl)-6-O-benzoyl-3-O-tertbutyldimethylsilyl- $\beta$-D-galactopyranosyl)-2-(2,2,2-trichloroethoxycarbonylamino)-2-deoxy- $\alpha$-D-

glucopyranoside (5). To a suspension of donor 4 (1.438 g, $2.66 \mathrm{mmol})$, acceptor 12 (926.7 mg, $0.886 \mathrm{mmol}), \mathrm{N}$ iodosuccinimide $\left(717.7 \mathrm{mg}, 3.191 \mathrm{mmol}\right.$ ), and MS4A powder (ca. $2.7 \mathrm{~g}$ ) in $\mathrm{CH}_{2} \mathrm{Cl}_{2}(17.7 \mathrm{~mL})$ was added trifluoromethanesulfonic acid $(31.2 \mu \mathrm{L}, 0.354 \mathrm{mmol})$ at $-40{ }^{\circ} \mathrm{C}$ under Ar atmosphere. After being stirred at -40 ${ }^{\circ} \mathrm{C}$ for 20 mins, the reaction was quenched with sat. $\mathrm{NaHCO}_{3}$ aq. and $10 \% \mathrm{Na}_{2} \mathrm{~S}_{2} \mathrm{O}_{3}$ aq. and extracted with $\mathrm{CHCl}_{3}$. The organic layer was dried over $\mathrm{Na}_{2} \mathrm{SO}_{4}$, filtered, and concentrated in vacuo. The residue was purified by silica-gel column chromatography (Toluene/AcOEt 20/1 to 10/1) to give $\mathbf{5}\left(1.139 \mathrm{~g}, 88 \%\right.$ ) as a white solid. ${ }^{1} \mathrm{H}$ NMR $\left(500 \mathrm{MHz}, \mathrm{CDCl}_{3}\right): \delta 8.01(\mathrm{~d}, J 7.3 \mathrm{~Hz}, 2 \mathrm{H}), 7.57(\mathrm{t}, J 7.4 \mathrm{~Hz}, 1 \mathrm{H}), 7.46(\mathrm{t}, J 7.7 \mathrm{~Hz}, 2 \mathrm{H}), 7.40-7.27(\mathrm{~m}, 20 \mathrm{H})$, 7.25-7.17 (m, 10H), 5.87-5.78 (m, 1H), $5.50(\mathrm{~d}, J 3.3 \mathrm{~Hz}, 1 \mathrm{H}), 5.23-5.17(\mathrm{~m}, 1 \mathrm{H}), 5.10(\mathrm{~d}, J 10.6 \mathrm{~Hz}, 1 \mathrm{H}), 5.03-$ $4.93(\mathrm{~m}, 5 \mathrm{H}), 4.89(\mathrm{~d}, J 3.4 \mathrm{~Hz}, 1 \mathrm{H}), 4.84-4.59(\mathrm{~m}, 9 \mathrm{H}), 4.54(\mathrm{~d}, J 11.0 \mathrm{~Hz}, 1 \mathrm{H}), 4.48(\mathrm{~d}, J 11.0 \mathrm{~Hz}, 1 \mathrm{H}), 4.41(\mathrm{~d}, J$ $12.2 \mathrm{~Hz}, 1 \mathrm{H}), 4.37-4.18(\mathrm{~m}, 3 \mathrm{H}), 4.14-4.04(\mathrm{~m}, 4 \mathrm{H}), 4.00-3.83(\mathrm{~m}, 4 \mathrm{H}), 3.69-3.64(\mathrm{~m}, 2 \mathrm{H}), 3.61-3.46(\mathrm{~m}, 3 \mathrm{H}), 1.14$ (d, J $6.4 \mathrm{~Hz}, 3 \mathrm{H}), 1.02(\mathrm{~d}, J 6.6 \mathrm{~Hz}, 1 \mathrm{H}), 0.88(\mathrm{~s}, 9 \mathrm{H}), 0.10(\mathrm{~s}, 3 \mathrm{H}), 0.05(\mathrm{~s}, 3 \mathrm{H}) .{ }^{13} \mathrm{C} \mathrm{NMR}\left(500 \mathrm{MHz}, \mathrm{CDCl}_{3}\right): \delta$ $176.37,138.90,138.65,138.61,138.57,138.46,138.10,133.61,133.08,130.00,129.62,129.48,128.45$, $128.42,128.34,128.30,128.27,128.24,128.21,128.14,128.12,128.03,128.00,127.92,127.67,127.57$, $127.53,127.51,127.47,127.41,127.31,127.25,127.13,117.27,100.95,97.40,93.96,80.26,79.15,77.59$, 77.31, 77.20, 77.05, 76.24, 76.09, 74.85, 74.61, 74.59, 74.20, 74.18, 73.28, 72.98, 72.76, 72.04, 71.93, 67.90, $66.72,66.26,26.09,17.90,16.73,16.59,-0.02,-3.30,-4.80$. HRMS (ESI-LTQ-Orbitrap) $\mathrm{m} / \mathrm{z}[\mathrm{M}+\mathrm{Na}]^{+}$calcd for $\mathrm{C}_{79} \mathrm{H}_{92} \mathrm{Cl}_{3} \mathrm{NO}_{17} \mathrm{SiNa}, 1484.5063$, found 1484.5074 .

Allyl 3,6-di-O-benzyl-4-O-(4-O-benzyl-2-O-(2,3,4-tri-O-benzyl- $\alpha$-L-fucopyranosyl)-6-O-benzoyl- $\beta$-Dgalactopyranosyl)-2-(2,2,2-trichloroethoxycarbonylamino)-2-deoxy- $\alpha$-D-glucopyranoside (13). To a solution of 5 (1.13 g, $0.773 \mathrm{mmol})$ in THF $(6.25 \mathrm{~mL})$ was added $70 \% \mathrm{HF}$.pyridine $(2.50 \mathrm{~mL})$ at rt under Ar atmosphere. After being stirred for $16 \mathrm{~h}$ at $\mathrm{rt}$, to the reaction mixture was added $70 \% \mathrm{HF}$.pyridine $(2.19 \mathrm{~mL})$ at $\mathrm{rt}$. After being stirred for $13.5 \mathrm{~h}$, the reaction mixture was diluted with $\mathrm{CHCl}_{3}$, quenched with sat. $\mathrm{NaHCO}_{3}$ aq., and extracted with $\mathrm{CHCl}_{3}$. The organic layer was dried over $\mathrm{Na}_{2} \mathrm{SO}_{4}$, filtered, and concentrated in vacuo. The residue was purified by silica-gel column chromatography (Toluene/AcOEt 20/1 to 9/1) to give 13 (894.4 mg, $86 \%)$ as a white solid. ${ }^{1} \mathrm{H} N M R\left(500 \mathrm{MHz}, \mathrm{CDCl}_{3}\right): \delta 7.98-7.94(\mathrm{~m}, 2 \mathrm{H}), 7.56(\mathrm{t}, J 7.4 \mathrm{~Hz}, 1 \mathrm{H}), 7.46-7.38(\mathrm{~m}, 6 \mathrm{H})$, 7.36-7.29 (m, 13H), 7.24-7.13 (m, 13H), 5.86-5.77 (m, 1H), 5.20 (dd, J 17.2, $1.4 \mathrm{~Hz}, 1 \mathrm{H}), 5.14(\mathrm{dd}, J 10.4,1.1 \mathrm{~Hz}$, $1 \mathrm{H}), 5.00-4.54(\mathrm{~m}, 17 \mathrm{H}), 4.38-4.23(\mathrm{~m}, 4 \mathrm{H}), 4.11-4.04(\mathrm{~m}, 3 \mathrm{H}), 3.96-3.87(\mathrm{~m}, 3 \mathrm{H}), 3.83(\mathrm{dd}, J 10.6,2.7 \mathrm{~Hz}, 1 \mathrm{H})$, 3.80-3.75 (m, 2H), 3.73-3.68 (m, 2H), 3.61-3.59 (br m, 1H), 3.57-3.47 (m, 4H), $1.02(\mathrm{~d}, J 6.4 \mathrm{~Hz}, 3 \mathrm{H}) .{ }^{13} \mathrm{C} \mathrm{NMR}$ $\left(500 \mathrm{MHz}, \mathrm{CDCl}_{3}\right): \delta 166.03,154.17,138.73,138.63,138.49,138.42,137.81,137.19,133.47,133.07,129.91$, $129.67,128.77,128.52,128.44,128.41,128.39,128.33,128.28,128.25,128.22,128.19,128.19,128.10$, 
$127.84,127.75,127.69,127.54,127.47,127.35,118.05,101.03,100.78,96.47,95.53,81.42,79.35,77.40$, 77.36, 77.22, 77.17, 75.43, 75.12, 74.79, 74.65, 74.61, 74.57, 73.89, 73.50, 72.96, 71.98, 70.59, 68.42, 67.93, $67.65,62.84,54.32,16.79$. HRMS (ESI-LTQ-Orbitrap) $\mathrm{m} / z[\mathrm{M}+\mathrm{Na}]^{+}$calcd for $\mathrm{C}_{73} \mathrm{H}_{78} \mathrm{Cl}_{3} \mathrm{NO}_{17} \mathrm{Na} 1370.4198$, found 1370.4225.

Allyl 2-acetamide-4-O-(3-O-acetyl-4-O-benzyl-2-O-(2,3,4-tri-O-benzyl- $\alpha$-L-fucopyranosyl)-6-O-benzoyl- $\beta$-Dgalactopyranosyl)-3,6-di-O-benzyl-2-deoxy- $\alpha$-D-glucopyranoside (14). To a solution of 13 (731.8 $\mathrm{mg}, 0.543$ $\mathrm{mmol}$ ) in THF (5.4 mL) and AcOH (5.4 mL) was added $\mathrm{Zn}-\mathrm{Cu}$ complex (ca. $1.40 \mathrm{~g}$ ) at rt under Ar atmosphere. After being stirred for $1.5 \mathrm{~h}$ at $\mathrm{rt}$, the reaction mixture was filtered, and concentrated in vacuo to give amine as a crude mixture. This crude mixture was used for next reaction. To a solution of crude product in pyridine (5.0 $\mathrm{mL}$ ) were added $\mathrm{Ac}_{2} \mathrm{O}(5.0 \mathrm{~mL})$ and $\mathrm{N}, \mathrm{N}$-dimethyl-4-aminopyridine $(6.7 \mathrm{mg}, 54.3 \mu \mathrm{mol})$ at $\mathrm{rt}$ under Ar atmosphere. After being stirred for $2.5 \mathrm{~d}$ at $\mathrm{rt}$, the reaction mixture was diluted with $\mathrm{CHCl}_{3}$, quenched with 1.0 $\mathrm{M} \mathrm{HCl}$ aq., and extracted with $\mathrm{CHCl}_{3}$. The organic layer was dried over $\mathrm{Na}_{2} \mathrm{SO}_{4}$, filtered, and concentrated in vacuo. The residue was purified by silica-gel column chromatography (Toluene/AcOEt 7/3) to give 14 (602.0 $\mathrm{mg}, 88 \%$ in 2 steps) as a light yellow oil. ${ }^{1} \mathrm{H} \mathrm{NMR}\left(500 \mathrm{MHz}, \mathrm{CDCl}_{3}\right): \delta 8.01-7.95(\mathrm{~m}, 2 \mathrm{H}), 7.60-7.55(\mathrm{~m}, 1 \mathrm{H}), 7.46$ (t, J $7.7 \mathrm{~Hz}, 2 \mathrm{H}), 7.38-7.18(\mathrm{~m}, 30 \mathrm{H}), 5.86-5.76(\mathrm{~m}, 1 \mathrm{H}), 5.28(\mathrm{~d}, J 8.7 \mathrm{~Hz}, 1 \mathrm{H}), 5.28(\mathrm{~d}, J 3.6 \mathrm{~Hz}, 1 \mathrm{H}), 5.18(\mathrm{dq}, J$ 17.2, $1.6 \mathrm{~Hz}, 1 \mathrm{H}), 5.11(\mathrm{dq}, J 10.5,1.2 \mathrm{~Hz}, 1 \mathrm{H}), 4.99(\mathrm{~d}, J 11.7 \mathrm{~Hz}, 1 \mathrm{H}), 4.91-4.87(\mathrm{~m}, 2 \mathrm{H}), 4.82(\mathrm{dd}, J 10.1,3.1 \mathrm{~Hz}$, $2 \mathrm{H}), 4.80(\mathrm{~d}, J 11.6 \mathrm{~Hz}, 2 \mathrm{H}), 4.72(\mathrm{~d}, J 12.1 \mathrm{~Hz}, 1 \mathrm{H}), 4.69-4.63(\mathrm{~m}, 4 \mathrm{H}), 4.57(\mathrm{~d}, J 11.6 \mathrm{~Hz}, 1 \mathrm{H}), 4.51(\mathrm{~d}, J 11.6 \mathrm{~Hz}$, $1 \mathrm{H}), 4.36(\mathrm{~d}, J 12.1 \mathrm{~Hz}, 1 \mathrm{H}), 4.30-4.03(\mathrm{~m}, 8 \mathrm{H}), 3.94-3.88(\mathrm{~m}, 2 \mathrm{H}), 3.82-3.74(\mathrm{~m}, 2 \mathrm{H}), 3.62-3.57(\mathrm{~m}, 2 \mathrm{H}), 3.54-$ $3.45(\mathrm{~m}, 3 \mathrm{H}), 1.87(\mathrm{~s}, 3 \mathrm{H}), 1.83(\mathrm{~s}, 3 \mathrm{H}), 1.13(\mathrm{~d}, J 6.4 \mathrm{~Hz}, 3 \mathrm{H}) .{ }^{13} \mathrm{C} \mathrm{NMR}\left(500 \mathrm{MHz}, \mathrm{CDCl}_{3}\right): \delta$ 170.22, 169.71, $165.89,138.89,138.68,138.55,138.53,137.79,137.77,133.74,133.17,129.71,129.66,129.60,129.01$, $128.57,128.46,128.38,128.34,128.30,128.21,128.17,128.14,127.85,127.83,127.78,127.75,127.62$, $127.55,127.35,127.24,125.27,117.40,100.71,98.01,96.50,79.19,77.40,76.54,76.36,75.10,74.99,74.68$, 74.30, 73.64, 73.42, 73.34, 73.25, 72.61, 71.75, 70.79, 68.13, 67.74, 66.77, 62.33, 51.96, 43.92, 23.32, 20.97, 16.68. HRMS (ESI-LTQ-Orbitrap) $m / z$ [M+Na] ${ }^{+}$calcd for $\mathrm{C}_{74} \mathrm{H}_{81} \mathrm{NO}_{17} \mathrm{Na} 1278.5397$, found 1278.5433.

Methyl 4-(2-acetamide-4-O-(3-O-acetyl-4-O-benzyl-2-O-(2,3,4-tri-O-benzyl- $\alpha$-L-fucopyranosyl)-6-O-benzoyl$\beta$-D-galactopyranosyl)-3,6-di-O-benzyl-2-deoxy- $\alpha$-D-glucopyranosyl)-2-ene-butyrate (15). To a solution of 14 (602.0 mg, $0.479 \mathrm{mmol})$ in $\mathrm{C}_{2} \mathrm{H}_{4} \mathrm{Cl}_{2}(9.6 \mathrm{~mL})$ were added methyl acrylate $(431 \mu \mathrm{L}, 4.79 \mathrm{mmol})$ and Grubbs catalyst 2 nd generation $\left(4.4 \mathrm{mg}, 5.18 \mu \mathrm{mol}\right.$ ) at rt under Ar atmosphere. After being stirred for $8.5 \mathrm{~h}$ at $50{ }^{\circ} \mathrm{C}$, to the reaction mixture was added Grubbs catalyst 2 nd generation $(8.1 \mathrm{mg}, 9.54 \mu \mathrm{mol})$ at $\mathrm{rt}$. After being stirred for $15.5 \mathrm{~h}$ at $50{ }^{\circ} \mathrm{C}$, to the reaction mixture was added Grubbs catalyst 2nd generation (12.0 mg, $\left.14.1 \mu \mathrm{mol}\right)$ at rt. After being stirred for $23 \mathrm{~h}$ at $50{ }^{\circ} \mathrm{C}$, the reaction mixture were added Grubbs catalyst 2 nd generation (12.6 $\mathrm{mg}, 14.8 \mu \mathrm{mol})$ and methyl acrylate $(210 \mu \mathrm{L}, 2.22 \mathrm{mmol})$ at rt. After being stirred for $17.5 \mathrm{~h}$, the reaction mixture was diluted with toluene and concentrated in vacuo. The residue was purified by silica-gel column chromatography (Toluene/AcOEt 5/1 to $3 / 2$ to $1 / 1$ ) to give 15 (246.4 mg, 40\%) as a light brown solid. ${ }^{1} \mathrm{H}$ NMR $\left(500 \mathrm{MHz}, \mathrm{CDCl}_{3}\right): \delta$ 8.00-7.96 $(\mathrm{m}, 2 \mathrm{H}), 7.60-7.55(\mathrm{~m}, 1 \mathrm{H}), 7.48-7.43(\mathrm{~m}, 2 \mathrm{H}), 7.38-7.16(\mathrm{~m}, 30 \mathrm{H}), 6.91(\mathrm{dt}, J$ $15.8,4.5 \mathrm{~Hz}, 1 \mathrm{H}), 5.97(\mathrm{dt}, J 15.8,1.9 \mathrm{~Hz}, 1 \mathrm{H}), 5.26(\mathrm{~d}, J 3.6 \mathrm{~Hz}, 1 \mathrm{H}), 5.23(\mathrm{~d}, J 8.2 \mathrm{~Hz}, 1 \mathrm{H}), 4.99(\mathrm{~d}, J 11.5 \mathrm{~Hz}, 1 \mathrm{H})$, $4.94(\mathrm{~d}, J 3.6 \mathrm{~Hz}, 1 \mathrm{H}), 4.89(\mathrm{~d}, J 11.5 \mathrm{~Hz}, 1 \mathrm{H}), 4.84(\mathrm{dd}, J$ 10.0, 3.2 Hz, 1H), $4.81(\mathrm{~d}, J 11.6 \mathrm{~Hz}, 1 \mathrm{H}), 4.73-4.63(\mathrm{~m}$, $5 \mathrm{H}), 4.62(\mathrm{~d}, J 11.5 \mathrm{~Hz}, 1 \mathrm{H}), 4.58(\mathrm{~d}, J 11.6 \mathrm{~Hz}, 1 \mathrm{H}), 4.51$ (d, J $11.5 \mathrm{~Hz}, 1 \mathrm{H}), 4.36(\mathrm{~d}, J 12.2 \mathrm{~Hz}, 1 \mathrm{H}), 4.31-4.22(\mathrm{~m}$, $3 \mathrm{H}), 4.20$ (dd, J 4.2, $1.9 \mathrm{~Hz}, 1 \mathrm{H}), 4.17-4.04(\mathrm{~m}, 6 \mathrm{H}), 3.88(\mathrm{~d}, J 2.9 \mathrm{~Hz}, 1 \mathrm{H}), 3.80$ (dd, J 11.0, 3.2 Hz, $1 \mathrm{H}), 3.76(\mathrm{dd}, J$ 10.2, $2.7 \mathrm{~Hz}, 1 \mathrm{H}), 3.72(\mathrm{~s}, 3 \mathrm{H}), 3.63(\mathrm{~d}, J 2.1 \mathrm{~Hz}, 1 \mathrm{H}), 3.61-3.47(\mathrm{~m}, 4 \mathrm{H}), 1.87(\mathrm{~s}, 3 \mathrm{H}), 1.83(\mathrm{~s}, 3 \mathrm{H}), 1.16(\mathrm{~d}, J 6.6$ $\mathrm{Hz}, 3 \mathrm{H}) .{ }^{13} \mathrm{C} \mathrm{NMR}\left(500 \mathrm{MHz}, \mathrm{CDCl}_{3}\right): \delta 170.22,169.79,166.22,165.88,143.33,138.68,138.65,138.52,137.75$, $137.69,133.17,129.69,129.64,128.57,128.44,128.37,128.35,128.30,128.27,128.24,128.17,128.13$, $127.86,127.79,127.73,127.59,127.53,127.51,127.22,121.12,100.83,98.11,96.96,79.17,77.84,76.69$, 76.46, 76.15, 75.08, 74.94, 74.89, 74.28, 73.90, 73.42, 73.40, 73.33, 72.44, 71.78, 71.14, 67.65, 66.84, 65.85, 
62.33, 52.06, 51.67, 23.23, 20.97, 16.66. HRMS (ESI-LTQ-Orbitrap) $m / z[\mathrm{M}+\mathrm{Na}]^{+}$calcd for $\mathrm{C}_{76} \mathrm{H}_{83} \mathrm{NO}_{19} \mathrm{Na}$ 1336.5452 , found 1336.5451 .

4-(2-Acetamide-4-O-(2-O-( $\alpha$-L-fucopyranosyl)- $\beta$-D-galactopyranosyl)-2-deoxy- $\alpha$-D-glucopyranosyl)butyric acid (16). To a solution of $15(297.6 \mathrm{mg}, 226.4 \mu \mathrm{mol})$ in ${ }^{\mathrm{t}} \mathrm{BuOH}(2.83 \mathrm{~mL}), \mathrm{AcOH}(1.13 \mathrm{~mL})$, and $\mathrm{H}_{2} \mathrm{O}(566 \mu \mathrm{L})$ was added palladium hydroxide on activated carbon ( $\mathrm{Pd} 20 \%$, wetted with ca.50\% water, $158.9 \mathrm{mg}, 1.13$ mmol) at rt. After being stirred for $8 \mathrm{~h}$ under $\mathrm{H}_{2}$ atmosphere with the pressure of $1.0 \mathrm{MPa}$, the reaction mixture was filtered through Hyflo Super-Cel ${ }^{\circledR}$ and concentrated in vacuo to give a crude mixture. This crude mixture was used for next reaction. To a solution of crude product in THF $(11.3 \mathrm{~mL})$ and $\mathrm{H}_{2} \mathrm{O}(11.3 \mathrm{~mL}) \mathrm{was}$ added $\mathrm{LiOH} \cdot \mathrm{H}_{2} \mathrm{O}(95.0 \mathrm{mg}, 2.26 \mathrm{mmol})$ at $0{ }^{\circ} \mathrm{C}$ under Ar atmosphere. After being stirred for $16 \mathrm{~h}$ at $\mathrm{rt}$, the reaction mixture was quenched with $\mathrm{AcOH}(130 \mu \mathrm{L})$, concentrated in vacuo, and lyophilized with $\mathrm{H}_{2} \mathrm{O}$. The residue was purified by gel filtration chromatography (MeOH) to give 16 (119.1 $\mathrm{mg}, 85 \%$ in 2 steps) as a white solid. ${ }^{1} \mathrm{H} N M R\left(500 \mathrm{MHz}, \mathrm{CD}_{3} \mathrm{OD}\right): \delta 5.24(\mathrm{~d}, J 3.3 \mathrm{~Hz}, 1 \mathrm{H}$, anomeric proton of GlcNAc), $4.76(\mathrm{~d}, J 3.6 \mathrm{~Hz}, 1 \mathrm{H}$, anomeric proton of Fuc), 4.49 (d, J $7.4 \mathrm{~Hz}, 1 \mathrm{H}$, anomeric proton of Gal), 4.21 (q, J $6.6 \mathrm{~Hz}, 1 \mathrm{H}$ ), 3.96 (dd, J 10.7, $3.6 \mathrm{~Hz}, 1 \mathrm{H}), 3.87-3.62(\mathrm{~m}, 14 \mathrm{H}), 3.56(\mathrm{dd}, J 7.7,4.2 \mathrm{~Hz}, 1 \mathrm{H}), 3.41(\mathrm{dt}, J 11.8,4.8 \mathrm{~Hz}, 1 \mathrm{H}), 2.31-2.18(\mathrm{~m}, 2 \mathrm{H}), 2.00$ (s, 3H), 1.91-1.84 (m, 2H), 1.20 (d, J $6.6 \mathrm{~Hz}, 3 \mathrm{H}) .{ }^{13} \mathrm{C}$ NMR (500 MHz, CD $\left.{ }_{3} \mathrm{OD}\right): \delta$ 173.67, 166.29, 102.37, 101.62, 98.52, 78.60, 78.32, 77.06, 75.42, 73.55, 72.54, 71.69, 71.00, 70.75, 70.57, 68.92, 68.14, 62.60, 61.53, 55.03, 27.61, 22.56, 16.78. HRMS (ESI-Q-TOF) $m / z$ [M-H] calcd for $\mathrm{C}_{24} \mathrm{H}_{40} \mathrm{NO}_{17} 614.2291$, found 614.2304.

Allyl 4-O-(3-O-(3,4,5-tri-O-acetyl-2-azide-2-deoxy- $\alpha$-D-galactopyranosyl)-4-O-benzyl-2-O-(2,3,4-tri-O-benzyl$\alpha$-L-fucopyranosyl)-6-O-benzoyl- $\beta$-D-galactopyranosyl)-3.6-di-O-benzyl-2-(2,2,2-

trichloroethoxycarbonylamino)-2-deoxy- $\alpha$-D-glucopyranoside (17). To a suspension of donor 6 (60.1 mg, $152.5 \mu \mathrm{mol})$, acceptor 13 (100.9 mg, $74.86 \mu \mathrm{mol})$, and MS4A powder (ca. $300 \mathrm{mg}$ ) in $\mathrm{CH}_{2} \mathrm{Cl}_{2}(748.6 \mu \mathrm{L}, 0.05 \mathrm{M})$ and toluene $\left(748.6 \mu \mathrm{L}, 0.05 \mathrm{M}\right.$ ) were added $\mathrm{Ag}_{2} \mathrm{CO}_{3}\left(42.1 \mathrm{mg}, 152.7 \mu \mathrm{mol}\right.$ ) and $\mathrm{AgClO}_{4}$ (about $9 \mathrm{mg}, 43.4 \mu \mathrm{mol}$ ) at $0{ }^{\circ} \mathrm{C}$ under $\mathrm{Ar}$ atmosphere. After being stirred for $13.5 \mathrm{~h}$ at $\mathrm{rt}$, the reaction mixture was filtered, washed with sat. $\mathrm{NaHCO}_{3}$ aq., and extracted with $\mathrm{CHCl}_{3}$. The organic layer was dried over $\mathrm{Na}_{2} \mathrm{SO}_{4}$, filtered, and concentrated in vacuo. The residue was purified by silica-gel column chromatography (toluene/EtOAc 15/1) to give 17 (111.7 mg, 90\%) as a white solid. ${ }^{1} \mathrm{H} \mathrm{NMR}\left(500 \mathrm{MHz}, \mathrm{CDCl}_{3}\right): \delta 7.99(\mathrm{t}, J 4.2 \mathrm{~Hz}, 2 \mathrm{H}), 7.56(\mathrm{tt}, J 7.4,1.5$ $\mathrm{Hz}, 1 \mathrm{H}), 7.50-7.43(\mathrm{~m}, 4 \mathrm{H}), 7.40-7.28(\mathrm{~m}, 19 \mathrm{H}), 7.24-7.12(\mathrm{~m}, 9 \mathrm{H}), 5.90-5.80(\mathrm{~m}, 1 \mathrm{H}), 5.55(\mathrm{~d}, J 4.0 \mathrm{~Hz}, 1 \mathrm{H}), 5.27-$ $5.17(\mathrm{~m}, 4 \mathrm{H}), 5.15-5.10(\mathrm{~m}, 2 \mathrm{H}), 5.06(\mathrm{~d}, J 11.3 \mathrm{~Hz}, 1 \mathrm{H}), 5.02-4.98(\mathrm{~m}, 2 \mathrm{H}), 4.91(\mathrm{~d}, J 3.6 \mathrm{~Hz}, 1 \mathrm{H}), 4.85(\mathrm{~d}, J 12.0$ $\mathrm{Hz}, 1 \mathrm{H}), 4.78-4.72(\mathrm{~m}, 3 \mathrm{H}), 4.69-4.55(\mathrm{~m}, 6 \mathrm{H}), 4.37(\mathrm{~d}, J 12.0 \mathrm{~Hz}, 1 \mathrm{H}), 4.30(\mathrm{dd}, J 11.2,6.0 \mathrm{~Hz}, 1 \mathrm{H}), 4.26-4.15(\mathrm{~m}$, $3 \mathrm{H}), 4.12-3.96(\mathrm{~m}, 7 \mathrm{H}), 3.94-3.86(\mathrm{~m}, 2 \mathrm{H}), 3.82-3.75(\mathrm{~m}, 2 \mathrm{H}), 3.72-3.67(\mathrm{~m}, 1 \mathrm{H}), 3.61-3.46(\mathrm{~m}, 5 \mathrm{H}), 3.37(\mathrm{t}, J 6.2$ $\mathrm{Hz}, 1 \mathrm{H}), 3.28(\mathrm{dd}, J$ 10.9, $3.2 \mathrm{~Hz}, 1 \mathrm{H}), 2.16(\mathrm{~s}, 3 \mathrm{H}), 2.05(\mathrm{~s}, 3 \mathrm{H}), 1.92(\mathrm{~s}, 3 \mathrm{H}), 1.15(\mathrm{~d}, J 6.6 \mathrm{~Hz}, 3 \mathrm{H}) .{ }^{13} \mathrm{C} \mathrm{NMR}(500$ $\mathrm{MHz}_{\mathrm{CDCl}}$ ): $\delta 170.87,169.74,169.59,166.08,154.19,139.56,138.74,138.71,138.63,138.56,137.91$, $133.68,133.11,129.92,129.70,129.03,128.59,128.50,128.46,128.30,128.22,128.11,128.08,128.06$, $127.90,127.78,127.68,127.64,127.44,127.35,127.27,127.05,125.30,117.60,100.45,97.53,97.47,96.69$, $95.49,79.95,77.84,77.47,77.23,76.38,76.26,75.63,75.25,74.86,74.68,74.64,74.49,74.38,73.52,72.13$, 72.02 , 70.97, 69.28, 68.28, 67.78, 67.69, 66.30, 62.92, 62.31, 59.32, 54.54, 53.42, 21.45, 20.65, 20.63, 20.46, 16.74. HRMS (ESI-LTQ-Orbitrap) $\mathrm{m} / z[\mathrm{M}+\mathrm{Na}]^{+}$calcd for $\mathrm{C}_{85} \mathrm{H}_{93} \mathrm{Cl}_{3} \mathrm{~N}_{4} \mathrm{O}_{24} \mathrm{Na}$, 1683.5108, found 1683.5104 .

Allyl 2-acetamide-4-O-(3-O-(2-acetamide-3,4,5-tri-O-acetyl-2-deoxy- $\alpha$-D-galactopyranosyl)-4- 0 -benzyl-2-O(2,3,4-tri-O-benzyl- $\alpha$-L-fucopyranosyl)-6-O-benzoyl- $\beta$-D-galactopyranosyl)-3.6-di-O-benzyl-2-deoxy- $\alpha$-D-

glucopyranoside (17a). To a solution of $17(622.2 \mathrm{mg}, 0.375 \mathrm{mmol})$ in THF (3.8 mL) and AcOH (3.8 mL) was added $\mathrm{Zn}$-Cu complex (ca. $1.90 \mathrm{~g}$ ) at rt under Ar atmosphere. After being stirred for $3 \mathrm{~h}$ at $\mathrm{rt}$, the reaction mixture was filtered, and concentrated in vacuo to give amine as a crude mixture. This crude mixture was used for next reaction. To a solution of crude product in pyridine $(6.0 \mathrm{~mL})$ was added $\mathrm{Ac}_{2} \mathrm{O}(6.0 \mathrm{~mL})$ at $\mathrm{rt}$ under $\mathrm{Ar}$ atmosphere. After being stirred for $1.5 \mathrm{~d}$ at $\mathrm{rt}$, the reaction mixture was diluted with $\mathrm{CHCl}_{3}$, quenched with 1.0 
$\mathrm{M} \mathrm{HCl}$ aq., and extracted with $\mathrm{CHCl}_{3}$. The organic layer was dried over $\mathrm{Na}_{2} \mathrm{SO}_{4}$, filtered, and concentrated in vacuo. The residue was purified by silica-gel column chromatography (Toluene/AcOEt 1/1) to give 17a (432.7 $\mathrm{mg}, 75 \%$ in 2 steps) as a white solid. ${ }^{1} \mathrm{H} \mathrm{NMR}\left(500 \mathrm{MHz}, \mathrm{CDCl}_{3}\right): \delta 7.99(\mathrm{~d}, J 7.3 \mathrm{~Hz}, 2 \mathrm{H}), 7.58(\mathrm{t}, J 7.4 \mathrm{~Hz}, 1 \mathrm{H})$, $7.47(\mathrm{t}, J 7.7 \mathrm{~Hz}, 2 \mathrm{H}), 7.42-7.27(\mathrm{~m}, 12 \mathrm{H}), 7.25-7.15(\mathrm{~m}, 18 \mathrm{H}), 5.89-5.79(\mathrm{~m}, 1 \mathrm{H}), 5.58-5.45(\mathrm{~m}, 2 \mathrm{H}), 5.32-5.17$ $(\mathrm{m}, 4 \mathrm{H}), 5.13-5.03(\mathrm{~m}, 2 \mathrm{H}), 5.01-4.87(\mathrm{~m}, 5 \mathrm{H}), 4.70-4.50(\mathrm{~m}, 11 \mathrm{H}), 4.43-4.24(\mathrm{~m}, 5 \mathrm{H}), 4.23-4.13(\mathrm{~m}, 3 \mathrm{H}), 4.08$ (dd, J 13.2, $5.1 \mathrm{~Hz}, 1 \mathrm{H}$ ), 4.00 (br s, 1H), 3.94 (dd, J 13.2, $5.7 \mathrm{~Hz}, 1 \mathrm{H}), 3.92-3.85(\mathrm{~m}, 3 \mathrm{H}), 3.76-3.54(\mathrm{~m}, 6 \mathrm{H}), 3.04$ (brs, 1H), 2.07 (s, 3H), $1.96(\mathrm{~s}, 3 \mathrm{H}), 1.87(\mathrm{~s}, 3 \mathrm{H}), 1.74(\mathrm{~s}, 3 \mathrm{H}), 1.51(\mathrm{~s}, 3 \mathrm{H}) .{ }^{13} \mathrm{C} \mathrm{NMR}\left(500 \mathrm{MHz}, \mathrm{CDCl}_{3}\right): \delta 170.53$, $170.40,170.13,169.94,169.73,165.99,139.14,138.86,138.45,138.15,138.03,137.64,133.81,133.30$, $129.66,129.60,128.53,128.48,128.34,128.30,128.26,128.24,128.18,127.92,127.72,127.68,127.58$, $127.50,127.41,127.18,127.15,126.57,117.06,100.82,98.36,96.46,80.42,77.64,76.82,75.92,75.50,74.65$, $73.72,73.64,73.47,72.10,71.38,71.07,68.59,67.94,67.65,67.12,66.79,62.85,52.10,47.06,23.29,22.62$, 20.62, 20.60, 20.43, 16.72. HRMS (ESI-LTQ-Orbitrap) $m / z$ [M+Na] ${ }^{+}$calcd for $\mathrm{C}_{86} \mathrm{H}_{98} \mathrm{~N}_{2} \mathrm{O}_{24} \mathrm{Na}, 1565.6402$, found 1565.6394.

Methyl 4-((2-acetamide-4-O-(3-O-(2-acetamide-3,4,5-tri-O-acetyl-2-deoxy- $\alpha$-D-galactopyranosyl)-4-Obenzyl-2-O-(2,3,4-tri-O-benzyl- $\alpha$-L-fucopyranosyl)-6-O-benzoyl- $\beta$-D-galactopyranosyl)-3.6-di-O-benzyl-2-

deoxy- $\alpha$-D-glucopyranosyl)-2-ene-butyrate (17b). To a solution of 17 a $(21.0 \mathrm{mg}, 13.6 \mu \mathrm{mol})$ in $\mathrm{C}_{2} \mathrm{H}_{4} \mathrm{Cl}_{2}(270$ $\mu \mathrm{L})$ were added methyl acrylate $(12.26 \mu \mathrm{L}, 136 \mu \mathrm{mol})$ and Grubbs catalyst 2nd generation $(2.34 \mathrm{mg}, 2.76 \mu \mathrm{mol})$ at $\mathrm{rt}$ under Ar atmosphere. After being stirred for $1 \mathrm{~h}$ at $50{ }^{\circ} \mathrm{C}$, the reaction mixture was added methyl acrylate $(12.25 \mu \mathrm{L}, 136 \mu \mathrm{mol})$ and Grubbs catalyst 2nd generation $(2.33 \mathrm{mg}, 2.74 \mu \mathrm{mol})$ at rt. After being stirred for 11 $\mathrm{h}$ at $50{ }^{\circ} \mathrm{C}$, the reaction mixture was heated to $80{ }^{\circ} \mathrm{C}$. After being stirred for $31.5 \mathrm{~h}$ at $80{ }^{\circ} \mathrm{C}$, the reaction mixture was diluted with toluene and concentrated in vacuo. The residue was purified by preparative layer chromatography $\left(\mathrm{CHCl}_{3} / \mathrm{MeOH} 3 / 1\right)$ to give $17 \mathrm{~b}(17.3 \mathrm{mg}, 79 \%)$ as a brown solid. ${ }^{1} \mathrm{H} \mathrm{NMR}\left(500 \mathrm{MHz}, \mathrm{CDCl}_{3}\right): \delta$ 8.02-7.97 (m, 2H), 7.61-7.56 (m, 1H), $7.47(\mathrm{t}, J 7.8 \mathrm{~Hz}, 2 \mathrm{H}), 7.41-7.16(\mathrm{~m}, 30 \mathrm{H}), 6.94(\mathrm{dt}, J 15.8,4.4 \mathrm{~Hz}, 1 \mathrm{H}), 6.00$ (dt, J 15.8, 2.0 Hz, 1H), 5.62 (brs, 1H), 5.47 (brs, 1H), 5.25-5.18 (m, 3H), 5.06 (dd, J 11.6, 3.2 Hz, 1H), 5.03-4.85 $(\mathrm{m}, 4 \mathrm{H}), 4.70-4.49(\mathrm{~m}, 10 \mathrm{H}), 4.46-4.21(\mathrm{~m}, 7 \mathrm{H}), 4.19-4.13(\mathrm{~m}, 2 \mathrm{H}), 4.10$ (ddd, J 16.1, 4.7, $2.0 \mathrm{~Hz}, 1 \mathrm{H}), 4.01$ (brs, $1 \mathrm{H}), 3.93-3.85(\mathrm{~m}, 3 \mathrm{H}),, 3.81(\mathrm{~s}, 1 \mathrm{H}), 3.78-3.52(\mathrm{~m}, 7 \mathrm{H}), 3.71(\mathrm{~s}, 3 \mathrm{H}), 2.08(\mathrm{~s}, 3 \mathrm{H}), 1.95(\mathrm{~s}, 3 \mathrm{H}), 1.86(\mathrm{~s}, 3 \mathrm{H}), 1.75$ $(\mathrm{s}, 3 \mathrm{H}), 1.51(\mathrm{~s}, 3 \mathrm{H}), 1.26(\mathrm{~s}, 3 \mathrm{H}) .{ }^{13} \mathrm{C} \mathrm{NMR}\left(500 \mathrm{MHz}, \mathrm{CDCl}_{3}\right): \delta 170.60,170.53,170.19,170.01,169.93,166.23$, $166.04,143.48,139.15,138.68,138.61,138.22,137.97,137.63,133.37,129.69,129.60,128.59,128.54$, $128.36,128.34,128.29,128.12,128.05,127.78,127.77,127.65,127.58,127.57,127.23,127.18,126.72$, 126.63, 120.99, 100.92, 98.33, 96.84, 80.23, 77.62, 75.86, 75.48, 75.10, 73.80, 73.72, 73.49, 72.10, 71.90, $71.72,71.04,68.53,67.85,67.65,67.12,66.88,65.68,62.86,52.19,51.77,47.08,23.27,22.65,20.68,20.66$, 20.49, 16.72. HRMS (ESI-LTQ-Orbitrap) $m / z[\mathrm{M}+\mathrm{Na}]^{+}$calcd for $\mathrm{C}_{88} \mathrm{H}_{100} \mathrm{~N}_{2} \mathrm{O}_{26} \mathrm{Na}$ 1623.6457, found 1623.6506.

4-(2-Acetamide-4-O-(3-O-(2-acetamide-2-deoxy- $\alpha$-D-galactopyranosyl)-2-O-( $\alpha$-L-fucopyranosyl)- $\beta$-D-

galactopyranosyl)-2-deoxy- $\alpha$-D-glucopyranosyl)butyric acid (18). To a solution of 17b (171.1 mg, $106.9 \mu \mathrm{mol})$ in ${ }^{t} \mathrm{BuOH}(1.34 \mathrm{~mL}), \mathrm{AcOH}(535 \mu \mathrm{L})$, and $\mathrm{H}_{2} \mathrm{O}(267 \mu \mathrm{L})$ was added palladium hydroxide on activated carbon ( $\mathrm{Pd}$ $20 \%$, wetted with ca.50\% water, $75.02 \mathrm{mg}, 534.3 \mu \mathrm{mol}$ ) at rt. After being stirred for $20.5 \mathrm{~h}$ under $\mathrm{H}_{2}$ atmosphere with the pressure of $1.0 \mathrm{MPa}$, the reaction mixture was filtered through Hyflo Super-Cel ${ }^{\circledR}$ and concentrated in vacuo to give a crude mixture. This crude mixture was used for next reaction. To a solution of crude product in THF $(5.3 \mathrm{~mL})$ and $\mathrm{H}_{2} \mathrm{O}(5.3 \mathrm{~mL})$ was added $\mathrm{LiOH} \cdot \mathrm{H}_{2} \mathrm{O}(45.2 \mathrm{mg}, 1.08 \mathrm{mmol})$ at $0{ }^{\circ} \mathrm{C}$ under $\mathrm{Ar}$ atmosphere. After being stirred for $24.5 \mathrm{~h}$ at $\mathrm{rt}$, the reaction mixture was quenched with $\mathrm{AcOH}(61.1 \mu \mathrm{L})$, concentrated in vacuo, and lyophilized with $\mathrm{H}_{2} \mathrm{O}$. The residue was purified by gel filtration chromatography (MeOH only) to give 18 (69.4 mg, 79\% in 2 steps) as a white solid. $\left.{ }^{1} \mathrm{H} \mathrm{NMR} \mathrm{(500} \mathrm{MHz,} \mathrm{CD}{ }_{3} \mathrm{OD}\right): \delta 5.33$ (d, J 3.9 $\mathrm{Hz}, 1 \mathrm{H}$, anomeric proton of GalNAc), $5.16(\mathrm{~d}, J 3.7 \mathrm{~Hz}, 1 \mathrm{H}$, anomeric proton of GlcNAc), 4.77 (d, J $3.6 \mathrm{~Hz}, 1 \mathrm{H}$, anomeric proton of Fuc), 4.53 (d, J $7.6 \mathrm{~Hz}, 1 \mathrm{H}$, anomeric proton of Gal), 4.37 (dd, J 13.0, 6.3 Hz, $1 \mathrm{H}$ ), 4.32 (dd, J 
11.0, 3.6 Hz, 1H), 4.18 (dd, J 6.6, $5.0 \mathrm{~Hz}, 1 \mathrm{H}), 4.11(\mathrm{~d}, J 2.6 \mathrm{~Hz}, 1 \mathrm{H}), 4.03-3.89(\mathrm{~m}, 4 \mathrm{H}), 3.86-3.61(\mathrm{~m}, 14 \mathrm{H}), 3.54$ (dd, J 7.2, 4.8 Hz, 1H), $3.42(\mathrm{dt}, J$ 11.6, $4.8 \mathrm{~Hz}, 1 \mathrm{H}), 2.37-2.23(\mathrm{~m}, 2 \mathrm{H}), 2.01(\mathrm{~d}, J 4.2 \mathrm{~Hz}, 6 \mathrm{H}), 1.91-1.86(\mathrm{~m}, 2 \mathrm{H})$, 1.21 (d, J $6.6 \mathrm{~Hz}, 3 \mathrm{H}$ ). ${ }^{13} \mathrm{C} \mathrm{NMR}\left(500 \mathrm{MHz}, \mathrm{CD}_{3} \mathrm{OD}\right): \delta$ 180.16, 174.47, 173.62, 102.11, 100.28, 98.53, 93.56, 78.45, 77.93, 76.85, 73.56, 73.47, 72.69, 72.65, 71.83, 71.17, 70.54, 70.01, 69.83, 68.70, 67.71, 64.95, 63.36,

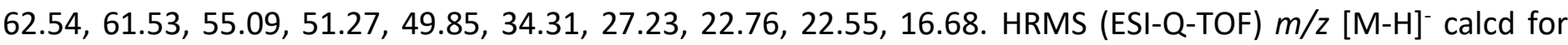
$\mathrm{C}_{32} \mathrm{H}_{53} \mathrm{~N}_{2} \mathrm{O}_{22}$ 817.3084, found 817.3113.

Allyl 3.6-di-O-benzyl-4-O-(4-O-benzyl-2-O-(2,3,4-tri-O-benzyl- $\alpha$-L-fucopyranosyl)-3-O-(2,3-di-O-benzyl-4,6-Obenzylidene- $\alpha$-D-galactopyranosyl)-6-O-benzoyl- $\beta$-D-galactopyranosyl)-2-(2,2,2-

trichloroethoxycarbonylamino)-2-deoxy- $\alpha$-D-glucopyranoside (19). To a suspension of donor 7 (26.3 mg, 47.4 $\mu \mathrm{mol})$, acceptor $13(20.3 \mathrm{mg}, 15.1 \mu \mathrm{mol}), N$-iodosuccinimide (12.6 mg, $56.0 \mu \mathrm{mol})$, and MS4A powder (ca. 63 $\mathrm{mg}$ ) in $\mathrm{CH}_{2} \mathrm{Cl}_{2}(301.2 \mu \mathrm{L})$ was added trifluoromethanesulfonic acid $(0.5 \mu \mathrm{L}, 5.66 \mu \mathrm{mol})$ at $-60{ }^{\circ} \mathrm{C}$ under $\mathrm{Ar}$ atmosphere. After being stirred for 30 mins at $-60{ }^{\circ} \mathrm{C}$, the reaction mixture was diluted with $\mathrm{CHCl}_{3}$, quenched with sat. $\mathrm{NaHCO}_{3}$ aq., and extracted with $\mathrm{CHCl}_{3}$. The organic layer was dried over $\mathrm{Na}_{2} \mathrm{SO}_{4}$, filtered, and concentrated in vacuo. The residue was purified by preparative layer chromatography (toluene/AcOEt $7 / 1$ ) to give 19 (24.5 $\mathrm{mg}, 91 \%)$ as a white solid.

${ }^{1} \mathrm{H}$ NMR $\left(500 \mathrm{MHz}_{\mathrm{CDCl}}\right.$ ): $\delta$ 7.97-7.92 (m, 2H), 7.57-7.52 (m, $\left.1 \mathrm{H}\right), 7.52-7.49(\mathrm{~m}, 2 \mathrm{H}), 7.46-7.39(\mathrm{~m}, 7 \mathrm{H}), 7.38-$ $7.26(\mathrm{~m}, 15 \mathrm{H}), 7.23-7.06(\mathrm{~m}, 23 \mathrm{H}), 5.87-5.78(\mathrm{~m}, 1 \mathrm{H}), 5.63(\mathrm{~d}, J 3.9 \mathrm{~Hz}, 1 \mathrm{H}), 5.39(\mathrm{~d}, J 2.6 \mathrm{~Hz}, 1 \mathrm{H}), 5.26(\mathrm{~s}, 1 \mathrm{H})$, 5.22-5.16 $(\mathrm{m}, 1 \mathrm{H}), 5.11-5.07(\mathrm{~m}, 1 \mathrm{H}), 5.01-4.95(\mathrm{~m}, 4 \mathrm{H}), 4.90(\mathrm{~d}, J 3.4 \mathrm{~Hz}, 1 \mathrm{H}), 4.77-4.61(\mathrm{~m}, 10 \mathrm{H}), 4.57(\mathrm{~d}, J$ $11.5 \mathrm{~Hz}, 1 \mathrm{H}), 4.49(\mathrm{t}, J 10.7 \mathrm{~Hz}, 2 \mathrm{H}), 4.35-4.25(\mathrm{~m}, 4 \mathrm{H}), 4.21-4.00(\mathrm{~m}, 7 \mathrm{H}), 3.99-3.93(\mathrm{~m}, 2 \mathrm{H}), 3.93-3.87(\mathrm{~m}, 1 \mathrm{H})$, 3.85-3.75 (m, 5H), $3.67(\mathrm{dd}, J$ 9.7, $2.6 \mathrm{~Hz}, 1 \mathrm{H}), 3.61-3.47(\mathrm{~m}, 5 \mathrm{H}), 3.40(\mathrm{~d}, J 12.0 \mathrm{~Hz}, 1 \mathrm{H}), 3.25(\mathrm{t}, J 6.4 \mathrm{~Hz}, 1 \mathrm{H})$, 1.17 (d, J $6.6 \mathrm{~Hz}, 3 \mathrm{H}) .{ }^{13} \mathrm{C}$ NMR $\left(500 \mathrm{MHz}, \mathrm{CDCl}_{3}\right): \delta$ 165.84, 154.17, 139.18, 138.67, 138.63, 138.60, 138.53, $138.39,138.10,137.96,137.92,133.64,130.06,129.89,129.66,128.54,128.38,128.29,128.25,128.19$, $128.10,128.03,127.96,127.94,127.83,127.70,127.64,127.57,127.44,127.34,127.25,127.20,126.33$, $117.43,100.77,100.51,97.46,97.23,96.53,95.45,80.59,80.23,76.39,76.09,75.69,74.97,74.91,74.78$, 74.62, 74.26, 74.19, 74.12, 73.62, 73.51, 72.25, 72.04, 71.33, 71.22, 69.25, 68.11, 67.96, 67.19, 66.20, 63.41, $62.70,54.49,33.88,28.55,16.70$. HRMS (ESI-LTQ-Orbitrap) $\mathrm{m} / z$ [M+Na] ${ }^{+}$calcd for $\mathrm{C}_{100} \mathrm{H}_{104} \mathrm{Cl}_{3} \mathrm{NO}_{22} \mathrm{Na}$, 1801.6012, found 1801.6016 .

Allyl 2-acetamide-3.6-di-O-benzyl-4-O-(4-O-benzyl-2-O-(2,3,4-tri-O-benzyl- $\alpha$-L-fucopyranosyl)-3-O-(2,3-di-Obenzyl-4,6-O-benzylidene- $\alpha$-D-galactopyranosyl)-6-O-benzoyl- $\beta$-D-galactopyranosyl)-2-deoxy- $\alpha$-D-

glucopyranoside (19a). To a solution of 19 (77.9 mg, $43.8 \mu \mathrm{mol})$ in THF (440 $\mu \mathrm{L})$ and AcOH (440 $\mu \mathrm{L})$ was added $\mathrm{Zn}$-Cu complex (ca. $80 \mathrm{mg}$ ) at rt under Ar atmosphere. After being stirred for $4.5 \mathrm{~h}$ at $\mathrm{rt}$, to the reaction mixture was added $\mathrm{Zn}$-Cu complex (ca. $84 \mathrm{mg}$ ). After being stirred for $2.5 \mathrm{~h}$ at $\mathrm{rt}$, the reaction mixture was filtered and concentrated in vacuo to give amine as a crude mixture. This crude mixture was used for next reaction. To a solution of crude product in pyridine $(2.0 \mathrm{~mL})$ was added $\mathrm{Ac}_{2} \mathrm{O}(2.0 \mathrm{~mL})$ at $\mathrm{rt}$ under $\mathrm{Ar}$ atmosphere. After being stirred for $6.5 \mathrm{~h}$ at $\mathrm{rt}$, the reaction mixture diluted with toluene and concentrated in vacuo. The reaction mixture was dissolved in $\mathrm{CHCl}_{3}$, washed with sat. $\mathrm{NaHCO}_{3}$ aq., and extracted with $\mathrm{CHCl}_{3}$. The organic layer was dried over $\mathrm{Na}_{2} \mathrm{SO}_{4}$, filtered, and concentrated in vacuo. The residue was purified by silica-gel column chromatography (toluene/AcOEt 35/1) to give 19a (71.0 mg, 99\% in 2 steps) as a light yellow oil. ${ }^{1} \mathrm{H}$ NMR $\left(500 \mathrm{MHz}, \mathrm{CDCl}_{3}\right): \delta$ 7.97-7.93 (m, 2H), 7.57-7.53 (m, 1H), 7.52-7.49 (m, 2H), 7.46-7.39 (m, 7H), 7.38-7.25 (m, 17H), 7.24-7.06 (m, 21H), 5.87-5.77 (m, 1H), $5.64(\mathrm{~d}, J 3.9 \mathrm{~Hz}, 1 \mathrm{H}), 5.40(\mathrm{~d}, J 2.6 \mathrm{~Hz}, 1 \mathrm{H}), 5.29-$ $5.25(\mathrm{~m}, 2 \mathrm{H}), 5.18(\mathrm{dd}, J 17.2,1.6 \mathrm{~Hz}, 1 \mathrm{H}), 5.08(\mathrm{dd}, J 10.4,1.6 \mathrm{~Hz}, 1 \mathrm{H}), 4.98(\mathrm{t}, J 10.1 \mathrm{~Hz}, 2 \mathrm{H}), 4.90(\mathrm{t}, J 5.2 \mathrm{~Hz}$, $2 \mathrm{H}), 4.73-4.60(\mathrm{~m}, 8 \mathrm{H}), 4.56(\mathrm{~d}, J 11.9 \mathrm{~Hz}, 1 \mathrm{H}), 4.51(\mathrm{~d}, J 3.3 \mathrm{~Hz}, 1 \mathrm{H}), 4.49(\mathrm{~d}, J 4.9 \mathrm{~Hz}, 1 \mathrm{H}), 4.38-4.25(\mathrm{~m}, 5 \mathrm{H})$, $4.21(\mathrm{dd}, J 11.0,6.6 \mathrm{~Hz}, 1 \mathrm{H}), 4.17-4.10(\mathrm{~m}, 3 \mathrm{H}), 4.09-4.00(\mathrm{~m}, 4 \mathrm{H}), 3.97-3.91(\mathrm{~m}, 2 \mathrm{H}), 3.87-3.75(\mathrm{~m}, 5 \mathrm{H}), 3.68$ $(\mathrm{dd}, J$ 9.7, $2.6 \mathrm{~Hz}, 1 \mathrm{H}), 3.62-3.55(\mathrm{~m}, 3 \mathrm{H}), 3.54-3.47(\mathrm{~m}, 1 \mathrm{H}), 3.44-3.38(\mathrm{~m}, 1 \mathrm{H}), 3.27(\mathrm{t}, J 6.7 \mathrm{~Hz}, 1 \mathrm{H}), 1.26(\mathrm{~s}$, 
3H), 1.20 (d, J $6.6 \mathrm{~Hz}, 3 \mathrm{H}) .{ }^{13} \mathrm{C} \mathrm{NMR}\left(500 \mathrm{MHz}, \mathrm{CDCl}_{3}\right): \delta 169.76,165.89,139.16,138.96,138.70,138.67$, $138.53,138.40,138.10,138.03,137.97,137.94,133.83,133.08,129.66,129.01,128.84,128.54,128.52$, $128.42,128.37,128.31,128.23,128.20,128.12,128.08,128.06,127.99,127.82,127.71,127.66,127.63$, $127.56,127.33,127.28,127.26,127.16,126.33,117.16,100.76,100.59,97.49,97.23,96.47,80.59,80.27$, 77.36, 77.32, 76.40, 76.10, 75.67, 75.03, 74.90, 74.80, 74.61, 74.56, 74.18, 74.12, 73.69, 73.67, 73.51, 72.29, $72.04,71.33,69.28,69.25,69.22,68.05,68.01,66.18,63.41,62.76,52.19,23.32,21.43,16.74$. HRMS (ESI-LTQOrbitrap) $\mathrm{m} / z[\mathrm{M}+\mathrm{Na}]^{+}$calcd for $\mathrm{C}_{99} \mathrm{H}_{105} \mathrm{NO}_{21} \mathrm{Na}, 1667.7105$, found 1667.7130 .

Methyl 4-((2-acetamide-3.6-di-O-benzyl-4-O-(4-O-benzyl-2-O-(2,3,4-tri-O-benzyl- $\alpha$-L-fucopyranosyl)-3-O(2,3-di-O-benzyl-4,6-O-benzylidene- $\alpha$-D-galactopyranosyl)-6-O-benzoyl- $\beta$-D-galactopyranosyl)-2-deoxy- $\alpha$ - $D-$

glucopyranosyl)-2-ene-butyrate (19b). To a solution of $19 a(20.2 \mathrm{mg}, 12.3 \mu \mathrm{mol})$ in $\mathrm{C}_{2} \mathrm{H}_{4} \mathrm{Cl}_{2}(246 \mu \mathrm{L}, 0.05 \mathrm{M})$ were added methyl acrylate $(11.0 \mu \mathrm{L}, 123 \mu \mathrm{mol})$ and Grubbs catalyst 2nd generation (1.03 $\mathrm{mg}, 1.21 \mu \mathrm{mol})$ at rt under Ar atmosphere. After being stirred for $1.5 \mathrm{~h}$ at $50{ }^{\circ} \mathrm{C}$, to the reaction mixture was added methyl acrylate $(11.0 \mu \mathrm{L}, 123 \mu \mathrm{mol})$ and Grubbs catalyst 2nd generation $(1.12 \mathrm{mg}, 1.32 \mu \mathrm{mol})$ at rt. After being stirred for 30 mins at $50{ }^{\circ} \mathrm{C}$, the reaction mixture was diluted with toluene and concentrated in vacuo. The residue was purified by preparative layer chromatography (toluene/AcOEt 1/4) to give $19 \mathrm{~b}(14.9 \mathrm{mg}, 71 \%)$ as a light yellow solid. ${ }^{1} \mathrm{H}$ NMR $\left(500 \mathrm{MHz}, \mathrm{CDCl}_{3}\right): \delta$ 7.97-7.93 (m, 2H), 7.58-7.53 (m, 1H), 7.52-7.48 (m, 2H), 7.46-7.39 (m, 6H), 7.37-7.32 (m, 7H), 7.30-7.06 (m, 32H), $6.93(\mathrm{dt}, J$ 15.8, $4.4 \mathrm{~Hz}, 1 \mathrm{H}), 5.98(\mathrm{dt}, J 15.8,1.9 \mathrm{~Hz}, 1 \mathrm{H}), 5.62(\mathrm{~d}, J 3.9 \mathrm{~Hz}$, $1 \mathrm{H}), 5.39(\mathrm{~d}, J 2.9 \mathrm{~Hz}, 1 \mathrm{H}), 5.25(\mathrm{~s}, 1 \mathrm{H}), 5.17(\mathrm{~d}, J 8.2 \mathrm{~Hz}, 1 \mathrm{H}), 5.01-4.94(\mathrm{~m}, 3 \mathrm{H}), 4.89(\mathrm{~d}, J 11.9 \mathrm{~Hz}, 1 \mathrm{H}), 4.72-$ $4.61(\mathrm{~m}, 7 \mathrm{H}), 4.57(\mathrm{~d}, J 11.9 \mathrm{~Hz}, 1 \mathrm{H}), 4.48(\mathrm{t}, J 11.4 \mathrm{~Hz}, 2 \mathrm{H}), 4.34(\mathrm{q}, J 6.5 \mathrm{~Hz}, 1 \mathrm{H}), 4.29(\mathrm{~d}, J 8.4 \mathrm{~Hz}, 2 \mathrm{H}), 4.27(\mathrm{~d}, J$ $8.6 \mathrm{~Hz}, 1 \mathrm{H}), 4.25-4.19(\mathrm{~m}, 2 \mathrm{H}), 4.17-4.02(\mathrm{~m}, 5 \mathrm{H}), 4.00(\mathrm{dd}, J 10.2,3.9 \mathrm{~Hz}, 1 \mathrm{H}), 3.93(\mathrm{~d}, J 2.4 \mathrm{~Hz}, 1 \mathrm{H}), 3.87-3.76$ $(\mathrm{m}, 5 \mathrm{H}), 3.71(\mathrm{~s}, 2 \mathrm{H}), 3.71-3.67(\mathrm{~m}, 1 \mathrm{H}), 3.66-3.64(\mathrm{~m}, 1 \mathrm{H}), 3.59(\mathrm{dd}, J 11.1,1.4 \mathrm{~Hz}, 1 \mathrm{H}), 3.57-3.47(\mathrm{~m}, 3 \mathrm{H}), 3.38$ (d, J $11.6 \mathrm{~Hz}, 1 \mathrm{H}), 3.28(\mathrm{t}, J 6.5 \mathrm{~Hz}, 1 \mathrm{H}), 1.86(\mathrm{~s}, 3 \mathrm{H}), 1.56(\mathrm{~s}, 3 \mathrm{H}), 1.26(\mathrm{~d}, J 6.5 \mathrm{~Hz}, 3 \mathrm{H}) .{ }^{13} \mathrm{C} \mathrm{NMR}(500 \mathrm{MHz}$, $\left.\mathrm{CDCl}_{3}\right): \delta 169.83,166.20,165.88,143.41,139.17,138.87,138.76,138.62,138.54,138.38,138.09,137.95$, $137.93,133.09,129.86,129.64,128.82,128.53,128.41,128.33,128.29,128.22,128.19,128.07,127.97$, $127.83,127.71,127.67,127.63,127.51,127.50,127.47,127.42,127.31,127.23,127.17,126.31,120.91$, $100.73,100.69,97.49,97.15,96.81,80.51,80.14,78.03,76.35,75.97,75.65,75.00,74.87,74.84,74.75,74.53$, 74.18, 74.12, 73.75, 73.60, 73.51, 72.07, 72.01, 71.70, 71.31, 69.21, 67.94, 66.23, 65.71, 63.39, 62.77, 52.29, 51.70, 23.24, 16.72. HRMS (ESI-Q-TOF) $\mathrm{m} / z$ [M+Na] $]^{+}$calcd for $\mathrm{C}_{101} \mathrm{H}_{107} \mathrm{NO}_{23} \mathrm{Na}, 1724.7126$, found 1724.7167.

4-(2-Acetamide-4-O-(2-O-( $\alpha$-L-fucopyranosyl)-3-O-( $\alpha$-D-galactopyranosyl)- $\beta$-D-galactopyranosyl)-2-deoxy- $\alpha$ D-glucopyranosyl)butyric acid (20). To a solution of $19 \mathrm{~b}(300.7 \mathrm{mg}, 177 \mu \mathrm{mol})$ in ${ }^{\mathrm{t}} \mathrm{BuOH}(2.21 \mathrm{~mL}), \mathrm{AcOH}(880$ $\mu \mathrm{L})$, and $\mathrm{H}_{2} \mathrm{O}(440 \mu \mathrm{L})$ was added palladium hydroxide on activated carbon (Pd 20\%, wetted with ca.50\% water, $124.1 \mathrm{mg}, 884 \mu \mathrm{mol}$ ) at rt. After being stirred for $12 \mathrm{~h}$ under $\mathrm{H}_{2}$ atmosphere with the pressure of 1.0 $\mathrm{MPa}$, the reaction mixture was filtered through Hyflo Super-Cel ${ }^{\circledR}$ and concentrated in vacuo to give a crude mixture. This crude mixture was used for next reaction. To a solution of crude product in THF $(9.0 \mathrm{~mL})$ and $\mathrm{H}_{2} \mathrm{O}$ $(9.0 \mathrm{~mL})$ was added $\mathrm{LiOH} \cdot \mathrm{H}_{2} \mathrm{O}(74.9 \mathrm{mg}, 1.79 \mathrm{mmol})$ at $0{ }^{\circ} \mathrm{C}$ under Ar atmosphere. After being stirred for $16.5 \mathrm{~h}$ at $\mathrm{rt}$, the reaction mixture was quenched with $\mathrm{AcOH}(100 \mu \mathrm{L})$, concentrated in vacuo, and lyophilized with $\mathrm{H}_{2} \mathrm{O}$. The residue was purified by gel filtration chromatography ( $\mathrm{MeOH}$ only) to give 20 (115.4 mg, 84\%) as a white solid. ${ }^{1} \mathrm{H} N M R\left(500 \mathrm{MHz}, \mathrm{CD}_{3} \mathrm{OD}\right): \delta 5.32(\mathrm{~d}, J 3.9 \mathrm{~Hz}, 1 \mathrm{H}$, anomeric proton of Gal (non-reducing terminal)), 5.16 (s, $1 \mathrm{H}$, anomeric proton of GlcNAc), $4.76(\mathrm{~d}, J 3.4 \mathrm{~Hz}, 1 \mathrm{H}$, anomeric proton of Fuc), $4.54(\mathrm{~d}, J 7.4 \mathrm{~Hz}, 1 \mathrm{H}$, anomeric proton of Gal), $4.35(\mathrm{q}, J 6.5 \mathrm{~Hz}, 1 \mathrm{H}), 4.17-4.11(\mathrm{~m}, 2 \mathrm{H}), 4.02-3.89(\mathrm{~m}, 4 \mathrm{H}), 3.88-3.55(\mathrm{~m}, 16 \mathrm{H}), 3.45-$ $3.38(\mathrm{~m}, 1 \mathrm{H}), 2.33-2.21(\mathrm{~m}, 2 \mathrm{H}), 2.00(\mathrm{~s}, 3 \mathrm{H}), 1.91-1.84(\mathrm{~m}, 2 \mathrm{H}), 1.20(\mathrm{~d}, J 6.5 \mathrm{~Hz}, 3 \mathrm{H}) .{ }^{13} \mathrm{C} \mathrm{NMR}(500 \mathrm{MHz}$, $\left.\mathrm{CD}_{3} \mathrm{OD}\right): \delta 180.79,173.65,102.19,100.36,98.59,96.10,79.76,78.58,76.68,73.69,73.62,73.12,72.65,71.84$, 71.44, 71.33, 71.18, 70.06, 69.93, 68.88, 67.70, 65.82, 63.35, 62.67, 61.58, 55.06, 49.90, 34.87, 27.51, 22.59, 16.70. HRMS (ESI-Q-TOF) $\mathrm{m} / z$ [M-H] $]^{-}$calcd for $\mathrm{C}_{30} \mathrm{H}_{50} \mathrm{NO}_{22}, 776.2819$, found 776.2836. 


\section{Materials and methods for bio assay}

Materials and cells. Raji cells were purchase from JCRB Cell Bank (JCRB9012). Roswell Park Memorial Institute (RMPI-1640; 189-02025), penicillin-Streptomycin Solution ( $\times 100 ; 168-23191)$, SDS-PAGE sample buffer solution (2ME+, $\times 4$; 191-13272) were purchased from FUJIFILM Wako Pure Chemical Corporation, Ltd. Fetal Bovine Serum (FBS; 10270-106), Trypan Blue Stain (0.4\%; 15250-061) were purchased from Thermo Fisher Scientific. 10\% gel (acrylamide gel, for SDS-PAGE) was purchased from Bio Craft (SDG521). 2D-Silver Stain-II and reagents for electrophoresis were purchased from Cosmo Bio Co., LTD (423413). Purified anti-human CD20 antibody (Isotype: Mouse IgG2b) was purchased from BioLegend, Inc (302302), Anti-B antigen antibody (sc-69952, Isotype: IgM) and anti-B antigen antibody fluorescently labeled with FITC (sc-69952 FITC, Isotype : IgM) was purchased from Santa cruz biotechnology. Thermo Fisher Scientific Attune NxT Acoustic Focusing Cytometer was used for flow cytometry analysis.

B antigen Labeling of cells using B antigen NHS ester 21. Raji cells (ca. $3.6 \times 10^{6}$ cells/tube) were incubated with two concentrations $(0,5.0 \mathrm{mM})$ of $B$ antigen ONSu ester 21 in PBS buffer $(\mathrm{pH} 7.4)$ at $37^{\circ} \mathrm{C}$ for 30 mins under a $\mathrm{CO}_{2}$ atmosphere. The suspension was centrifuged at $1600 \times \mathrm{g}$ for $3 \mathrm{mins}$ at $\mathrm{rt}$, and the cells were washed three times with PBS buffer.

Protocol for B antigen-antibody conjugates using B antigen NHS ester 21. Anti-CD20 antibody (80 $\mu \mathrm{L}, 40 \mu \mathrm{g})$ was transferred into $50 \mathrm{kDa}$ Amicon ultra $(0.5 \mathrm{~mL})$ and PBS $(300 \mu \mathrm{L})$ was added. The solution was centrifuged under $14,000 \times \mathrm{g}$ for 10 mins at $4{ }^{\circ} \mathrm{C}$. To the supernatant was then added PBS (300 $\left.\mu \mathrm{L}\right)$. The step of centrifugation and PBS addition was repeated for three times. After the antibody was divided equally into 3 tubes (10 $\mathrm{gg}$ in $50 \mu \mathrm{L}$ PBS buffer), the B antigen NHS ester $\mathbf{2 1}$ at two concentrations (final concentrations: 0, 1.0 and $5.0 \mathrm{mM}$ ) were added to antibody solution and mixed by pipetting. After being incubated for $30 \mathrm{mins}$ at $4{ }^{\circ} \mathrm{C}$, the reaction mixture (in $50 \mathrm{kDa}$ Amicon ultra) was centrifuged under $14,000 \times \mathrm{g}$ for $10 \mathrm{mins}$ at $4{ }^{\circ} \mathrm{C}$. To the supernatant was then added PBS $(350 \mu \mathrm{L})$. The step of centrifugation and PBS addition was repeated for five times to give $\mathrm{B}$ antigen-antibody conjugates. These antibodies were stored at $4{ }^{\circ} \mathrm{C}$ for short term (1-2 weeks).

SDS PAGE analysis. 10\% gel (acrylamide gel) was used. To $0.4 \mu \mathrm{g}$ of sample (antibody alone or B antigenantibody conjugates) in $13 \mu \mathrm{L}$ PBS buffer were added $5 \mu \mathrm{L}$ SDS-PAGE sample buffer (4×) and $2 \mu \mathrm{L} 1.0 \mathrm{M}$ dithiothreitol solution in PBS buffer, and heated at $100{ }^{\circ} \mathrm{C}$ for 5 mins. $3 \mu \mathrm{L}$ standard protein marker was used. After loading the samples to the gels, SDS-PAGE were run using Tris-Glycine buffer (25 mM Tris, $192 \mathrm{mM}$ glycine and $0.1 \% \mathrm{SDS}$ ) at $200 \mathrm{~V}$ for $1 \mathrm{~h}$. The gels were immediately stained with silver stain kit reagents (2DSilver Stain-II) and scanned using ImageQuantTM LAS 500. After measuring the distance from the top of the gel to each MW marker band (210, 140, 90, 70, 55, 40, 35, $20 \mathrm{kDa})$, MW was plotted against the distance and a logarithmic approximation curve was drawn. The MW of target band was estimated using this curve.

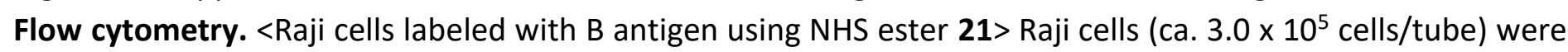
incubated with anti-B antigen antibody fluorescently labeled with FITC (clone: Z5H-2, $2 \mu \mathrm{L}$ in $98 \mu \mathrm{L}$ PBS buffer, 1:50) on ice for $1 \mathrm{~h}$. The cells were washed twice and suspended in $0.3 \mathrm{~mL}$ of PBS buffer and analyzed with flow cytometer.

$<$ Raji cells labeled with B antigen-antibody conjugates> Raji cells (ca. $3.0 \times 10^{5}$ cells/tube) were incubated with B antigen-antibody conjugates ( $0.1 \mu \mathrm{g}$ in $100 \mu \mathrm{L}$ PBS buffer) or PBS buffer on ice for $1 \mathrm{~h}$. The cells were washed three times with PBS buffer and incubated with Alexa Fluro ${ }^{\circledR} 488$-goat anti-mouse IgG antibody (0.05 $\mu \mathrm{L}$ in 100 $\mu \mathrm{L}$ PBS buffer, 1:2000) or anti-B antigen antibody fluorescently labeled with FITC (clone: $25 \mathrm{H}-2,2 \mu \mathrm{L}$ in $98 \mu \mathrm{L}$ PBS buffer, 1:50) on ice for $1 \mathrm{~h}$. The cells were washed twice and suspended in $0.3 \mathrm{~mL}$ of PBS buffer and analyzed with flow cytometer. 


\section{Acknowledgements}

This work was financially supported in part by JSPS KAKENHI Grant Number $15 \mathrm{H} 05836$ in Middle Molecular Strategy, JSPS KAKENHI Grant Number 16H05924, JSPS KAKENHI Grant Number 19KK0145, JSPS KAKENHI Grant Number 20H00404, JSPS KAKENHI Grant Number 20K05727, and JSPS KAKENHI Grant Number $2 \mathrm{OH} 04709$.

\section{Supplementary Material}

Supplementary data $\left({ }^{1} \mathrm{H}\right.$ and ${ }^{13} \mathrm{C}$ NMR spectra) can be found in the online version.

\section{References}

1. Fuster, M. M.; Esko, J. D. Nat. Rev. Cancer 2005, 5, 526. https://doi.org/10.1038/nrc1649

2. van Kooyk, Y.; Rabinovich, G. A. Nat. Immunol. 2008, 9, 593. https://doi.org/10.1038/ni.f.203

3. Lichtenstein, R. G.; Rabinovich, G. A. Cell Death Differ. 2013, 20, 976. https://doi.org/10.1038/cdd.2013.50

4. Landsteiner, K. Zentralbl. Bakteriol. 1900, 27, 357.

5. Amjadi, O.; Rafiei, A.; Ajami, A.; Valadan, R.; Janbaabaei, G. Research in Molecular Medicine 2015, 3, 1.

6. Marionneau, S.; Ruvoën, N.; Le Moullac-Vaidye, B.; Clement, M.; Cailleau-Thomas, A.; Ruiz-Palacois, G.; Huang, P.; Jiang, X.; Le Pendu, J. Gastroenterology 2002, 122, 1967. https://doi.org/10.1053/gast.2002.33661

7. Aspholm-Hurtig, M.; Dailide, G.; Lahmann, M.; Kalia, A.; Ilver, D.; Roche, N.; Vikström, S.; Sjöström, R.; Lindén, S.; Bäckström, A.; Lundberg, C.; Arnqvist, A.; Mahdavi, J.; Nilsson, U. J.; Velapatiño, B.; Gilman, R. H.; Gerhard, M.; Alarcon, T.; López-Brea, M.; Nakazawa, T.; Fox, J. G.; Correa, P.; Dominguez-Bello, M. G.; Perez-Perez, G. I.; Blaser, M. J.; Normark, S.; Carlstedt, I.; Oscarson, S.; Teneberg, S.; Berg, D. E.; Borén, T. Science 2004, 305, 519.

8. Lemieux, R. U.; Driguez, H. J. Am. Chem. Soc. 1975, 97, 4069. https://doi.org/10.1021/ja00847a034

9. Paulsen, H.; Kolář, Č. Angew. Chem. Int. Ed. 1978, 17, 771. https://doi.org/10.1002/anie.197807711

10. Paulsen, H.; Kolář, Č. Tetrahedron Lett. 1979, 20, 2881. https://doi.org/10.1016/S0040-4039(01)86441-8

11. Milat, M.-L.; Sinaÿ, P. Carbohydr. Res. 1981, 92, 183.

12. Bovin, N. V.; Zurabyan, S. É.; Khorlin, A. Y. Bulletin of the Academy of Sciences of the USSR, Division of chemical science 1982, 31, 1023. https://doi.org/10.1007/BF00949960

13. Pazynina, G. V.; Tyrtysh, T. V.; Bovin, N. V. Mendeleev Commun. 2002, 12, 143. https://doi.org/10.1070/MC2002v012n05ABEH001653 
14. Korchagina, E. Y.; Ryzhov, I. M.; Byrgazov, K. A.; Popova, I. S.; Pokrovsky, S. N.; Bovin, N. V. Mendeleev Commun. 2009, 19, 152.

https://doi.org/10.1016/j.mencom.2009.05.013

15. Meloncelli, P. J.; Lowary, T. L. Aust. J. Chem. 2009, 62, 558.

https://doi.org/10.1071/CH09058

16. Meloncelli, P. J.; Lowary, T. L. Carbohydr. Res. 2010, 345, 2305.

https://doi.org/10.1016/i.carres.2010.08.012

17. Ryzhov, I. M.; Korchagina, E. Y.; Popova, I. S.; Bovin, N. V. Carbohydr. Res. 2012, 351, 17. https://doi.org/10.1016/i.carres.2011.12.013

18. Hara, A.; Imamura, A.; Ando, H.; Ishida, H.; Kiso, M. Molecules 2013, 19, 414. https://doi.org/10.3390/molecules19010414

19. Karki, G.; Mishra, V. N.; Mandal, P. K. Glycoconjugate J. 2016, 33, 63.

https://doi.org/10.1007/s10719-015-9635-1

20. Griffin, Matthew E.; Hsieh-Wilson, Linda C. Cell Chem. Biol. 2016, 23, 108.

https://doi.org/10.1016/j.chembiol.2015.12.007

21. Prescher, J. A.; Dube, D. H.; Bertozzi, C. R. Nature 2004, 430, 873.

https://doi.org/10.1038/nature02791

22. Zeng, Y.; Ramya, T. N. C.; Dirksen, A.; Dawson, P. E.; Paulson, J. C. Nat. Methods 2009, 6, 207. https://doi.org/10.1038/nmeth.1305

23. Hui, J.; Bao, L.; Li, S.; Zhang, Y.; Feng, Y.; Ding, L.; Ju, H. Angew. Chem. Int. Ed. 2017, 56, 8139. https://doi.org/10.1002/anie.201703406

24. Boyce, M.; Carrico, I. S.; Ganguli, A. S.; Yu, S.-H.; Hangauer, M. J.; Hubbard, S. C.; Kohler, J. J.; Bertozzi, C. R. Proc. Natl. Acad. Sci. U.S.A. 2011, 108, 3141.

https://doi.org/10.1073/pnas.1010045108

25. Zheng, T.; Jiang, H.; Gros, M.; Soriano del Amo, D.; Sundaram, S.; Lauvau, G.; Marlow, F.; Liu, Y.; Stanley, P.; Wu, P. Angew. Chem. Int. Ed. 2011, 50, 4113. https://doi.org/10.1002/anie.201100265

26. Mbua, N. E.; Li, X.; Flanagan-Steet, H. R.; Meng, L.; Aoki, K.; Moremen, K. W.; Wolfert, M. A.; Steet, R.; Boons, G.-J. Angew. Chem. Int. Ed. 2013, 52, 13012.

https://doi.org/10.1002/anie.201307095

27. Tang, F.; Zhou, M.; Qin, K.; Shi, W.; Yashinov, A.; Yang, Y.; Yang, L.; Guan, D.; Zhao, L.; Tang, Y.; Chang, Y.; Zhao, L.; Yang, H.; Zhou, H.; Huang, R.; Huang, W. Nat. Chem. Biol. 2020, 16, 766. https://doi.org/10.1038/s41589-020-0551-8

28. Frame, T.; Carroll, T.; Korchagina, E.; Bovin, N.; Henry, S. Transfusion 2007, 47, 876. https://doi.org/10.1111/i.1537-2995.2007.01204.x

29. Huang, M. L.; Smith, R. A. A.; Trieger, G. W.; Godula, K. J. Am. Chem. Soc. 2014, 136, 10565. https://doi.org/10.1021/ja505012a

30. Hudak, J. E.; Canham, S. M.; Bertozzi, C. R. Nat. Chem. Biol. 2014, 10, 69. https://doi.org/10.1038/nchembio.1388

31. Paszek, M. J.; DuFort, C. C.; Rossier, O.; Bainer, R.; Mouw, J. K.; Godula, K.; Hudak, J. E.; Lakins, J. N.; Wijekoon, A. C.; Cassereau, L.; Rubashkin, M. G.; Magbanua, M. J.; Thorn, K. S.; Davidson, M. W.; Rugo, H. S.; Park, J. W.; Hammer, D. A.; Giannone, G.; Bertozzi, C. R.; Weaver, V. M. Nature 2014, 511, 319. https://doi.org/10.1038/nature13535 
32. Pulsipher, A.; Griffin, M. E.; Stone, S. E.; Brown, J. M.; Hsieh-Wilson, L. C. J. Am. Chem. Soc. 2014, 136, 6794.

https://doi.org/10.1021/ja5005174

33. Pulsipher, A.; Griffin, M. E.; Stone, S. E.; Hsieh-Wilson, L. C. Angew. Chem. Int. Ed. 2015, 54, 1466. https://doi.org/10.1002/anie.201409258

34. Srivastava, G.; Kaur, K. J.; Hindsgaul, O.; Palcic, M. M. J. Biol. Chem. 1992, 267, 22356.

35. Tsutsui, M.; Sianturi, J.; Masui, S.; Tokunaga, K.; Manabe, Y.; Fukase, K. Eur. J. Org. Chem. 2020, 2020, 1802.

https://doi.org/10.1002/ejoc.201901809

36. Jiang, L.; Chan, T.-H. Tetrahedron Lett. 1998, 39, 355.

https://doi.org/10.1016/S0040-4039(97)10599-8

37. Tanaka, S.-i.; Takashina, M.; Tokimoto, H.; Fujimoto, Y.; Tanaka, K.; Fukase, K. Synlett 2005, $2005,2325$.

38. Veeneman, G. H.; van Leeuwen, S. H.; van Boom, J. H. Tetrahedron Lett. 1990, 31, 1331. https://doi.org/10.1016/S0040-4039(00)88799-7

39. Wong, C.-H.; Ye, X.-S.; Zhang, Z. J. Am. Chem. Soc. 1998, 120, 7137. https://doi.org/10.1021/ja9813616

40. Paulsen, H.; Richter, A.; Sinnwell, V.; Stenzel, W. Carbohydr. Res. 1978, 64, 339. https://doi.org/10.1016/S0008-6215(00)83722-2

41. Paulsen, H.; Schultz, M.; Klamann, J.-D.; Waller, B.; Paal, M. Liebigs Ann. Chem. 1985, 1985, 2028. https://doi.org/10.1002/jlac.198519851011

42. Zhang, Z.; Ollmann, I. R.; Ye, X.-S.; Wischnat, R.; Baasov, T.; Wong, C.-H. J. Am. Chem. Soc. 1999, $121,734$. https://doi.org/10.1021/ja982232s

43. Sianturi, J.; Manabe, Y.; Li, H.-S.; Chiu, L.-T.; Chang, T.-C.; Tokunaga, K.; Kabayama, K.; Tanemura, M.; Takamatsu, S.; Miyoshi, E.; Hung, S.-C.; Fukase, K. Angew. Chem. Int. Ed. 2019, 58, 4526. https://doi.org/10.1002/anie.201812914

44. Mammen, M.; Choi, S.-K.; Whitesides, G. M. Angew. Chem. Int. Ed. 1998, 37, 2754.

45. Cecioni, S.; Imberty, A.; Vidal, S. Chem. Rev. 2015, 115, 525. https://doi.org/10.1021/cr500303t

46. Gestwicki, J. E.; Strong, L. E.; Kiessling, L. L. Chem. Biol. 2000, 7, 583. https://doi.org/10.1016/S1074-5521(00)00002-8

47. Gestwicki, J. E.; Kiessling, L. L. Nature 2002, 415, 81. https://doi.org/10.1038/415081a

48. Kiessling, L. L.; Gestwicki, J. E.; Strong, L. E. Angew. Chem. Int. Ed. 2006, 45, 2348. https://doi.org/10.1002/anie.200502794

49. Edberg, S. C.; Bronson, P. M.; Van Oss, C. J. Immunochemistry 1972, 9, 273. https://doi.org/10.1016/0019-2791(72)90092-4

50. Goldstein, B. Biophys. Chem. 1975, 3, 363. https://doi.org/10.1016/0301-4622(75)80030-5 